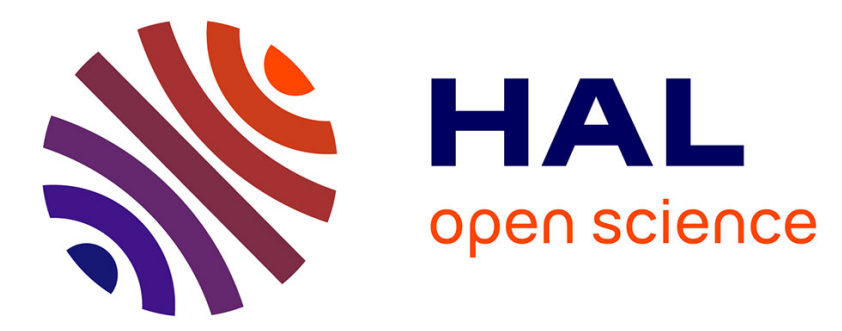

\title{
Long horizon predictability: An asset allocation perspective
}

\author{
Abraham Lioui, Patrice Poncet
}

\section{To cite this version:}

Abraham Lioui, Patrice Poncet. Long horizon predictability: An asset allocation perspective. European Journal of Operational Research, 2019, 278, pp.961 - 975. 10.1016/j.ejor.2019.04.040 . hal03484415

\section{HAL Id: hal-03484415 \\ https://hal.science/hal-03484415}

Submitted on 20 Dec 2021

HAL is a multi-disciplinary open access archive for the deposit and dissemination of scientific research documents, whether they are published or not. The documents may come from teaching and research institutions in France or abroad, or from public or private research centers.
L'archive ouverte pluridisciplinaire HAL, est destinée au dépôt et à la diffusion de documents scientifiques de niveau recherche, publiés ou non, émanant des établissements d'enseignement et de recherche français ou étrangers, des laboratoires publics ou privés.

\section{다)(1) $(5$}

Distributed under a Creative Commons Attribution - NonCommercial| 4.0 International 


\title{
LONG Horizon PREDICTABILITY: An Asset Allocation Perspective.*
}

\author{
Abraham Lioui ${ }^{\dagger} \quad$ Patrice Poncet ${ }^{\ddagger}$
}

24th April 2019

\begin{abstract}
Consider investors with a 10-year investment horizon who rebalance their portfolio at the monthly frequency. Should they use information from monthly returns, 10-year returns or intermediate returns to build their optimal portfolios? When stock and bond returns are i.i.d., the frequency of returns is not relevant. However, when they are predictable, it is. Using a new estimation approach and before correcting for overlapping observations, we show that the positive impact of predictability on investors' welfare is stronger for longer prediction horizons and the more so as the investment horizon enlarges. This welfare improvement is achieved by adopting realistic portfolio positions. When we correct for the persistence in the predictive regression residuals due to overlapping observations, our results are preserved for short to medium investment horizons although the added value of long horizon predictability is reduced. Our results are robust to various checks and also hold out-of-sample. Overall, short to medium term investors should exploit long horizon predictability even though they rebalance their portfolios at high frequency.
\end{abstract}

JEL classification: E43, E52, G11, G12.

Keywords: finance, dynamic portfolio decision, predictive regression, long horizon predictability, inter-temporal hedging.

*We thank the Editor, Emanuele Borgonovo, and three anonymous referees for very useful comments and suggestions which have significantly improved the quality of this paper. We acknowledge helpful remarks and discussions from seminar participants at HEC Montréal, EDHEC Business School, ISFA-Lyon, ESSEC Business School, ParisDauphine University, the 2nd Symposium in Empirical Finance and Financial Econometrics organized by SMU and ESSEC Business School in Singapore, and the 30th International Conference organized in behalf of the French Finance Association by EMLyon Business School. We thank in particular Tolga Cenesizoglu, Gilles Chemla, Pascal François, Andras Fulop, René Garcia, Olivier Lecourtois, François Le Grand, Junye Li, Francesco Menoncin, Frank Moraux, Lorenzo Naranjo, François Quittard-Pinon and Raman Uppal. Special thanks are due to François Cocquemas for excellent research assistance. All remaining errors are of course our own.

${ }^{\dagger}$ EDHEC Business School, France. abraham.lioui@edhec.edu. Postal address: EDHEC Business School, 393, Promenade des anglais, 06202 Nice, France. Tel: 33 (0)4 93187868.

${ }_{\ddagger}^{\ddagger}$ ESSEC Business School, France. poncet@essec.fr. Corresponding Author. Postal address: ESSEC Business School, 3, avenue Bernard Hirsch, 95021 Cergy-Pontoise Cedex, France. Tel: 33 (0)1 34433026. 


\section{Introduction}

In the wake of the pioneering work by Fama and French (1988), Campbell and Shiller (1988) and Stambaugh (1999), many researchers believe and use what constitutes the "academic conventional wisdom" of weak predictability of financial asset returns at short horizons and stronger predictability at long ones. ${ }^{1}$ Long horizon predictability (hereafter LHP) seems convincing, as the adjusted $R^{2}$ s of the predictive regressions increase considerably with the length of the return period. The key econometric argument of LHP defenders in view of this evidence is that using long horizon returns reduces the noise in asset returns. Rossi et al. (2013), computing a new standard error for predictive regressions that does not impose the null hypothesis that equity returns are unpredictable, even showed that LHP is stronger than previously acknowledged. Adopting an alternative methodology, Wang et al. (2018) reached the same conclusion.

Support for this view, however, was not universal. Some authors claimed that the improvement in $R^{2} \mathrm{~s}$ is largely spurious, the main culprits being the persistence in variables generated by the use of overlapping observations and the persistence in predictors. When persistence is cleansed away, LHP could at times be more delusive than short horizon predictability. Boudoukh et al. (2008) even argued that stock return LHP must be discarded as a myth. Ross (2005) used an asset pricing model to set up bounds on predictability as an alternative way to convince that the observed LHP is spurious. Moreno and Olmeda (2007) claimed that predictability is not exploitable for trading purposes if transaction costs are taken into account. Fama and French (2018) documented that the distribution of continuously compounded long-term returns tend to be normally distributed. Yet, recent research in favor of LHP contests these findings. Carmona et al. (2012) find that executive stock options are not fairly valued unless stock return predictability is accounted for. Huang and Zhou (2017) and to a lesser extent Poti (2018) show that the bounds offered by Ross (2005) are all violated in the data since they rest on an asset pricing model which in general performs poorly. Madan and Schoutens (2018) flatly reject Fama and French's (2018) findings of normally distributed long-run returns.

More significantly, a new stream of research argues that predictors operate at different frequencies or "scales", leading to scale-specific predictability. ${ }^{2}$ For instance, Fuster et al. (2010) and Bianchi and Tamoni (2017) show that the hump-shaped dynamics in many predictors can hardly be reconciled with low-order models. Dew-Becker and Giglio (2016) derive scale-specific risk prices that reflect the prices of risk of consumption fluctuations at various frequencies to assess whether short or long term risks are priced in the equity market. Favero et al. (2017) use various predictorbased variance bounds of the pricing kernel to discriminate leading classes of asset pricing models. Similarly, Bandi et al. (2018) provide strong evidence that different predictors exhibit explanatory

\footnotetext{
${ }^{1}$ See for instance the standard textbooks by Campbell et al. (1997) and Cochrane (2005), or the surveys by Barberis and Thaler (2003) and Koijen and Van Nieuwerburgh (2011) among many others.

${ }^{2}$ A pioneering paper by Calvet and Fisher (2007) had already shown that the dividend yield dynamics is driven by shocks with heterogeneous persistence levels, and investigated their impact on asset return predictability.
} 
power at different frequencies. All this evidence implies that standard predictive systems are too restrictive return generating processes and that a whole range of frequency-specific expected returns can be exploited. Two main consequences follow: i) using long-term projection of short-term returns in lieu of genuine long-term returns is not compatible with the data, which justifies LHP, and ii) there are neither theoretical nor empirical reasons why the $R^{2}$ of predictive regressions should increase monotonically with the prediction horizon. Our contribution is to explore the implications of these two findings for optimal asset allocation.

The debate in the literature cited above thus has mostly centered on estimation and inference issues, not on applications to actual asset allocation. Regarding the latter, arguing that rational investors should use parameters estimated from the predictive regression yielding the best goodnessof-fit, independently of their portfolio rebalancing horizon misses a crucial point. First, in a static framework, the individual having a one-month investment horizon will obviously choose the parameters derived from a one-month return period, even though the (say) four-year return period leads to a much larger $R^{2}$. Second, in a dynamic setting, should a ten-year investment horizon investor who rebalances her portfolio very frequently adopt the one-month prediction horizon or, say, the ten-year one? The answer is not clear: If different return periods in fact lead to different estimated parameters, as the recent literature on estimation and inference issues cited above demonstrates, a model misspecification problem arises when the investor's prediction horizon, on the one hand, and her decision interval and/or investment horizon, on the other hand, do not coincide. Therefore, arbitrarily adopting a given return period to estimate the parameters of the data generating process of the traded assets' returns may result in substantial welfare losses.

Given the practical importance of this issue, the literature on exploiting LHP for portfolio allocation purposes is surprisingly scant. ${ }^{3}$ In particular, the portfolio and welfare implications of the evidence that estimates obtained using LHP differ markedly from those obtained from short return periods have not been addressed. As a typical example, Brennan and Xia (2010) study the impact of predictability on dynamic asset allocation, but their estimates for long horizon returns are mechanically inferred from those obtained with short term (one month) returns and then differ from those directly found in the data. There is by construction no additional information contained in their long horizon returns. A rare counter-example is Carroll et al. (2017) who find that there is a trade-off in portfolio optimization between forecasting horizon, rebalancing frequency and transaction costs due to the time-varying nature of correlation between asset returns.

What can a long term investor really achieve by exploiting LHP thus remains an open issue on which this paper intends to shed light. Our main objective is to investigate the welfare implications of the differences between short- and long-horizon predictability. The estimation procedure we adopt sharply differs from what is offered in the asset allocation literature. The standard method consists in estimating the parameters of $\mathrm{AR}(1)$ processes for the predictors and one-period $(h=1)$ asset excess returns, and then deriving the dynamics of the $h$-period excess returns ( $h$ integer and

\footnotetext{
${ }^{3}$ For reviews, see Brandt (2010), Wachter (2010) and Campbell (2017).
} 
$\geq 2$ ) from forward recursion of the one-period return process. Consequently, the parameters for the predictors and the asset excess returns are known, deterministic functions of the parameters of the initial processes and no information is gained by varying the prediction horizon. The investor's dynamic portfolio strategy then is left unaffected by a change in that horizon. In sharp contrast, we use long horizon returns that are the truly observed (realized) ones and estimate the parameters of the data generating processes with these realized returns. Our recommendation to the long-term investor is to adopt the prediction horizon $(h)$ that yields the highest expected utility of wealth for a given investment horizon $(T)$. The return period thus optimally selected will not in general be the one for which the $R^{2}$ is maximum, as what counts for the investor is the portfolio's risk-return reward (such as the Sharpe ratio), not the $R^{2}$.

Our economic setting, estimation procedures and main findings can be summarized as follows. The investor is endowed with CRRA utility and operates in an arbitrage-free, frictionless but incomplete market, in which trading in a stock index, a constant-maturity long term bond and a locally riskless asset takes place continuously. In the empirical analysis, we use US monthly data for the 76-year period spanning 1942:M1 to 2016:M12. We adopt the standard assumption that the stock index and long term bond excess returns are predicted by the dividend yield and the default spread. The prediction horizon $h$ spans one month to ten years, and the investor's horizon $T$ is varied from one month to thirty years.

For each individual prediction horizon $h$, we derive the continuous time parameters, using OLS to estimate the discretized processes. Our first main contribution is to provide renewed and convincing evidence that the estimation procedure has a strong impact on the parameters of the dynamic processes involved (see the recent papers by Bianchi and Tamoni (2017), Dew-Becker and Giglio (2016), Favero et al. (2017), and Bandi et al. (2018)). Estimating the parameters of the predictive regressions and of the stock and bond excess returns for long prediction horizons taken individually rather than mechanically inferring them from those obtained from the oneperiod horizon leads to significantly different loadings on the dividend yield and the default spread, regression $R^{2} \mathrm{~s}$, and conditional and unconditional volatilities of the stock and bond excess returns. The latter conform more closely to those actually observed since they are estimated from true long period returns.

We then assess the potential value added by LHP. We compare, for each investment horizon $T$, the optimal portfolio's certainty equivalent $(C E)$ rates of return obtained by exploiting predictability at various horizons. Our second main contribution is to show that using a prediction horizon different from one month i) leads to larger $C E$ rates, albeit ii) to a markedly smaller extent than could be anticipated from the predictive regression $R^{2} \mathrm{~s}$. The investor's welfare tends to increase with the length of the prediction period, for all investment horizons, although the relationship is not monotonic. We also show that ignoring the time variability in excess returns decreases substantially the long-term investors' welfare.

We then investigate whether these results survive the correction for overlapping observations. 
As a third main contribution, we show that a drastic correction, borrowed from Valkanov (2003), for the persistence in the predictive regression residuals created by overlapping data fairly confirms previous findings. In particular, the estimated stock and bond (conditional) volatilities decrease. Although, when comparing the certainty equivalents for long (beyond 10 years) investment horizons, the added value of LHP disappears, it is still strongly present for all short and medium investment horizons (up to 3 years) for all prediction horizons, and for medium term (from 5 to 7 years) investors for medium to long (at and beyond 5 years) prediction horizons. Therefore, in sample, the economic value added by LHP is not an artefact due to overlapping observations.

In the final step, we perform an analysis for prediction and investment horizons up to five years to check whether our main in-sample results survive out of sample. For prediction horizons up to four years, our tests confirm that LHP increases investors' welfare.

The remainder of the paper is structured as follows. Section 2 describes the economy and derives the individual's optimal dynamic portfolio strategy. Section 3 details our estimation procedures. Section 4 presents the data and provides the estimated parameters for the dynamics of the predictors and the stock and bond excess returns estimated by OLS. Section 5 analyzes the impact of stock and bond return predictability on the investor's optimal strategy, portfolio composition and welfare. Section 6 corrects for overlapping observations and compares the results with those obtained in Section 4. In Section 7 we run an out-of-sample analysis. Section 8 concludes. To save space, all technical derivations and proofs are left to the companion Internet Appendix, which also provides additional analytical and empirical results.

\section{The dynamic asset allocation model}

We describe the economy in which the investor operates and then derive her optimal portfolio strategy and the normalized certainty equivalent of her optimal terminal wealth.

\subsection{The economy}

We consider a frictionless and arbitrage-free financial market in which trading takes place continuously. There are three assets available for trade, a riskless asset, a stock (the market portfolio, or simply the market) and a long lived, constant maturity bond. Following Yao et al. (2016), we assume that the instantaneous interest rate $r_{t}$ follows the mean-reverting process:

$$
d r_{t}=\theta_{r}\left[\bar{r}-r_{t}\right] d t+\sigma_{r} d Z_{r, t}
$$

The parameters $\theta_{r}$ (speed of mean reversion) and $\sigma_{r}$ are constant and $\bar{r}$ is the long term value of the riskless rate. $Z_{r, t}$ is a one-dimensional Brownian motion under the physical probability measure, as will be all our subsequent (correlated) Brownian motions $Z_{x, t}$. Together with mean 
reverting market prices of risk, the specification given by Eq. (1) belongs to the class of extensively used affine dynamic term structure models. ${ }^{4}$

The value $M_{t}$ of the market portfolio is assumed to evolve according to the stochastic differential equation (SDE):

$$
\frac{d M_{t}}{M_{t}}-r_{t} d t=\mu_{M, t} d t+\sigma_{M} d Z_{M, t}
$$

where $\mu_{M, t}$ denotes its time-varying expected excess return and $\sigma_{M}$ its constant instantaneous conditional volatility. Note that its square computed over a finite interval $\left(\sigma_{M}^{2} t\right)$ is not the market unconditional variance for this interval since the expected excess return $\mu_{M, t}$ is stochastic. $Z_{M, t}$ is a Brownian motion whose correlation with $Z_{r, t}$ is denoted by $\rho_{r, M}$.

The value $B_{t}$ of the constant maturity bond is assumed to obey the SDE:

$$
\frac{d B_{t}}{B_{t}}-r_{t} d t=\mu_{B, t} d t+\sigma_{B} d Z_{B, t}
$$

where $\mu_{B, t}$ denotes its time-varying expected excess return and $\sigma_{B}$ its constant instantaneous conditional volatility. ${ }^{5} Z_{B, t}$ is a Brownian motion whose correlations with $Z_{M, t}$ and $Z_{r, t}$ are denoted by $\rho_{B, M}$ and $\rho_{r, B}$, respectively. Excess returns on bonds of different maturities are not perfectly correlated since the predictors influence them variously across the yield curve. This justifies using distinct $Z_{r}$ and $Z_{B}$.

Stock and bond excess returns vary in some predictors. To avoid perfect correlation between the premia associated with these assets, we assume a bivariate predictive regressions. Using $z_{1, t}$ and $z_{2, t}$ as predictors, we assume the following affine structure:

$$
\begin{aligned}
\mu_{M, t} & =\mu_{M, 0}+\mu_{M, 1} z_{1, t}+\mu_{M, 2} z_{2, t} \\
\mu_{B, t} & =\mu_{B, 0}+\mu_{B, 1} z_{1, t}+\mu_{B, 2} z_{2, t}
\end{aligned}
$$

where $\mu_{i, 0}, \mu_{i, 1}$ and $\mu_{i, 2}$ are constants for $i=M, B$. We keep the simple mean reverting specification for the dynamics of the predictors:

$$
d z_{i, t}=\theta_{i}\left[\overline{z_{i}}-z_{i, t}\right] d t+\sigma_{z_{i}} d Z_{z_{i}, t}, \forall i=1,2
$$

where the parameters $\theta_{i}, \sigma_{z_{i}}, \rho_{i, M}, \rho_{i, B}, \rho_{i, r}(i=1,2)$ and $\rho_{1,2}$ (the correlation between the Brownian increments $d Z_{z_{1}}$ and $d Z_{z_{2}}$ ) are constant, and $\overline{z_{i}}$ is the long term value towards which $z_{i, t}$ converges. The mean-reverting specification is equivalent to the discrete time $\mathrm{AR}(1)$ process. Its use, common in portfolio theory, suits well our purpose to keep the framework as standard as possible, so as to focus on the impact of LHP and ease the comparison with the literature. The two predictors are

\footnotetext{
${ }^{4}$ See the review in Schmidt (2011).

${ }^{5}$ The same remark as for $\sigma_{M}$ applies. Note additionally that this assumption does not make much violence to the data since the bond has a constant (long) maturity.
} 
correlated through their own respective correlation with the stock, the bond and the interest rate, as well as through their direct correlation (if $\rho_{1,2} \neq 0$ ). Note that the presence of either one of the two sources of risk $Z_{z_{i}, t}$ makes the financial market incomplete.

\subsection{The investor's optimal portfolio strategy}

The household has an investment horizon $T$ and maximizes the expected utility of her terminal wealth $V_{T}$, subject to adopting an admissible, self-financing strategy. She is endowed with a power utility function $U\left(V_{T}\right)$ :

$$
U\left(V_{T}\right)=\frac{V_{T}^{1-\gamma}}{1-\gamma},
$$

where the constant $\gamma(>0$ and $\neq 1)$ is her relative risk aversion coefficient. A decisive advantage of ignoring intermediate consumption is that an exact and quasi-explicit solution obtains even under incomplete markets (see for instance Kim and Omberg (1996)), which is not the case with interim consumption, even with power utility.

We denote by $\omega_{M, t}$ and $\omega_{B, t}$ the proportion of the household's wealth invested in the stock and in the bond, respectively. She solves the program:

$$
\begin{aligned}
& \underset{\left\{\omega_{t}\right\}}{\operatorname{Max}} E_{t}\left[\frac{V_{T}^{1-\gamma}}{1-\gamma}\right] \\
\text { s.t. } & \frac{d V_{t}}{V_{t}}=r_{t} d t+\omega_{M, t}\left[\frac{d M_{t}}{M_{t}}-r_{t} d t\right]+\omega_{B, t}\left[\frac{d B_{t}}{B_{t}}-r_{t} d t\right],
\end{aligned}
$$

and also subject to Eqs. (1) to (6).

In the Internet Appendix we show that the investor's optimal portfolio allocation is:

$$
\begin{aligned}
{\left[\begin{array}{l}
\omega_{M, t} \\
\omega_{B, t}
\end{array}\right] } & =\frac{1}{\gamma} \Sigma^{-1}\left[\begin{array}{r}
\mu_{M, 0}+\mu_{M, 1} z_{1, t}+\mu_{M, 2} z_{2, t} \\
\mu_{B, 0}+\mu_{B, 1} z_{1, t}+\mu_{B, 2} z_{2, t}
\end{array}\right] \\
& +\frac{A_{1}(T-t)}{\gamma} \Sigma^{-1} \Sigma_{r} \\
& +\frac{A_{2}(T-t)+A_{22}(T-t) z_{1, t}+A_{4}(T-t) z_{2, t}}{\gamma} \Sigma^{-1} \Sigma_{1} \\
& +\frac{A_{3}(T-t)+A_{33}(T-t) z_{2, t}+A_{4}(T-t) z_{1, t}}{\gamma} \Sigma^{-1} \Sigma_{2},
\end{aligned}
$$

where the $(2 \times 2)$ variance-covariance matrix $\Sigma$ of asset returns and the $(2 \times 1)$ vectors of covariances $\Sigma_{r}, \Sigma_{1}$ and $\Sigma_{2}$ are defined in the Internet Appendix, and the complicated $A_{i}(T-t)$ and $A_{j j}(T-t)$ functions (along with the function $A_{0}(T-t)$ ) are obtained from the system of ordinary differential equations derived therein. The structure of this strategy is standard in an affine model. The first component is the mean-variance term and the last three terms are Merton-Breeden intertemporal 
hedges against unfavorable shifts in the predictors and the interest rate that affect the stock and bond excess returns. The portfolio weight allocated to the riskless asset is equal to $\left(1-\omega_{M, t}-\omega_{B, t}\right)$. We underline that in such a dynamic setting, even though the utility is defined for a given, fixed, investment horizon, the solution to the intertemporal optimization program involves horizon effects as evidenced by the presence of $(T-t)$ in equation (9). There is no exogenous horizon dependence beyond the investor's investment horizon $(T)$.

To compute the value at time $t$ of the indirect utility function induced by the optimal strategy, we need in particular to know $\omega_{M, t}$ and $\omega_{B, t}$. The latter weights depend on the variables $z_{1, t}$ and $z_{2, t}$ and, directly or through the $A_{i}(T-t)$ and $A_{j j}(T-t)$ functions, on the following set of 27 parameters: $\mu_{M, 0}, \mu_{M, 1}, \mu_{M, 2}, \mu_{B, 0}, \mu_{B, 1}, \mu_{B, 2}, \sigma_{M}, \sigma_{B}, \sigma_{r}, \sigma_{z_{1}}, \sigma_{z_{2}}, \rho_{B, M}, \rho_{r, M}, \rho_{r, B}, \rho_{1, M}, \rho_{2, M}$, $\rho_{1, B}, \rho_{2, B}, \rho_{1, r}, \rho_{2, r}, \rho_{1,2}, \theta_{r}, \theta_{1}, \theta_{2}, \bar{r}, \overline{z_{1}}$ and $\overline{z_{2}}$. These will be obtained by means of the estimation procedure described in Section 3. It is important to note that the set of parameters is derived for a given prediction horizon (return period) $h$. Crucially, all our estimated parameters then will genuinely depend on $h$, instead of being either independent from it or mechanically proportional to it (see Section 3.2).

This step once completed, we can compute the optimal strategy and the certainty equivalent of the random (annualized) rate of return achieved over the investment horizon. Denoting by $J(t,$. the investor's value function at date $t(0 \leq t \leq T)$ and by $C E O W$ the certainty equivalent of the investor's optimal wealth, we have:

$$
\frac{C E O W(t, T)^{1-\gamma}}{1-\gamma}=J(t, T, .)=\frac{V_{t}^{1-\gamma}}{1-\gamma} e^{G\left(T-t, r_{t}, z_{1, t}, z_{2, t}\right)}
$$

where

$$
\begin{aligned}
G\left(T-t, r_{t}, z_{1, t}, z_{2, t}\right) & \equiv A_{0}(T-t)+A_{1}(T-t) r_{t}+A_{2}(T-t) z_{1, t} \\
& +\frac{1}{2} A_{22}(T-t) z_{1, t}^{2}+A_{3}(T-t) z_{2, t}+\frac{1}{2} A_{33}(T-t) z_{2, t}^{2} \\
& +A_{4}(T-t) z_{1, t} z_{2, t}
\end{aligned}
$$

Evaluating at initial date $t=0$, and normalizing initial wealth by setting $V_{0}=\$ 1$, we can compute the certainty equivalent of the investor's optimal terminal wealth in dollar terms. $C E O W(0, T)$ is the amount of wealth to be obtained at the investment horizon $T$ with certainty that would yield the same expected utility as the one derived from investing $\$ 1$ optimally at date $t=0$. Then calculating $\ln C E O W(0, T) / T \equiv C E$, as done in Brennan and Xia (2010), yields the annualized certainty equivalent rate of return. $C E$ can be compared to the average value of the risk-free rate over the investment horizon $T$ or the market yield on the zero-coupon bond maturing at date $T$. The main advantage of computing $C E$ rates is that comparing results across different prediction 
horizons or different risk aversion levels is immediate. ${ }^{6}$

\section{$3 \quad$ Estimation procedures}

To compute the certainty equivalent return rates of the strategies, we identify first the parameters for the dynamics of the predictors, the interest rate, and the stock and bond excess returns. Then we estimate the parameters using actual data. We set $h$, the prediction horizon the investor deems appropriate, equal to $\Delta t, 2 \Delta t, \ldots, H \Delta t$, where $\Delta t$ is the length of the discrete interval between actual observations (one month) and $H \Delta t$ is the longest prediction horizon.

\subsection{Short horizon predictability}

We discuss first the standard case of short horizon predictability, i.e. $h=\Delta t$. We skip here unessential details, as the procedure is well known (see for instance Bandi and Perron (2008) or Cochrane (2005)), and will be more explicit in the next subsection. As observed data are discrete, we must use a discretized version of each continuous process. Therefore, we integrate the continuous time dynamics Eq. (6) over the discrete time interval $[t, t+\Delta t]$, which yields:

$$
z_{i, t+\Delta t}=\overline{z_{i}}\left(1-e^{-\theta_{i} \Delta t}\right)+e^{-\theta_{i} \Delta t} z_{i, t}+\sigma_{z_{i}} e^{-\theta_{i}(t+\Delta t)} \int_{t}^{t+\Delta t} e^{\theta_{i} s} d Z_{z_{i}, s}, \quad \forall i=1,2 .
$$

We then identify the integrated process parameters with those of the discrete time regressions:

$$
z_{i, t+\Delta t}=a_{z_{i}, \Delta t}+A_{z_{i}, \Delta t} z_{i, t}+v_{z_{i}, t, t+\Delta t}, \quad \forall i=1,2
$$

Next we estimate the parameters for the dynamics of the stock and bond excess returns. For

the stock market, we integrate the continuous time process Eq. (2), using Eq. (4), over the discrete interval $[t, t+\Delta t]$ and obtain:

$$
\begin{aligned}
\ln M_{t+\Delta t}-\ln M_{t}-\int_{t}^{t+\Delta t} r_{s} d s & =\left(\mu_{M, 0}-\frac{\sigma_{M}^{2}}{2}\right) \Delta t+\mu_{M, 1}\left(\Delta t-\frac{1}{\theta_{1}}\left(1-e^{-\theta_{1} \Delta t}\right)\right) \overline{z_{1}} \\
& +\mu_{M, 2}\left(\Delta t-\frac{1}{\theta_{2}}\left(1-e^{-\theta_{2} \Delta t}\right)\right) \overline{z_{2}} \\
& -\mu_{M, 1} \frac{1}{\theta_{1}}\left(e^{-\theta_{1} \Delta t}-1\right) z_{1, t}-\mu_{M, 2} \frac{1}{\theta_{2}}\left(e^{-\theta_{2} \Delta t}-1\right) z_{2, t} \\
& +\int_{t}^{t+\Delta t} \sigma_{M} d Z_{M, s}+\mu_{M, 1} \frac{1}{\theta_{1}} \sigma_{z_{1}} \int_{t}^{t+\Delta t}\left(1-e^{-\theta_{1}(t+\Delta t)} e^{\theta_{1} s}\right) d Z_{z_{1}, s} \\
& +\mu_{M, 2} \frac{1}{\theta_{2}} \sigma_{z_{2}} \int_{t}^{t+\Delta t}\left(1-e^{-\theta_{2}(t+\Delta t)} e^{\theta_{2} s}\right) d Z_{z_{2}, s} .
\end{aligned}
$$

\footnotetext{
${ }^{6}$ As a supplement, we explore in the Internet Appendix the economic cost induced by a standard "myopic" strategy, which ignores intertemporal hedging, by computing the associated sub-optimal $C E$ rates.
} 
We apply the same technique to the constant-maturity bond excess returns to obtain a similar expression for $\ln B_{t+\Delta t}-\ln B_{t}-\int_{t}^{t+\Delta t} r_{s} d s$.

We then identify the integrated process parameters with those of the discrete time regressions:

$$
\begin{gathered}
r_{M, t, t+\Delta t}-\int_{t}^{t+\Delta t} r_{s} d s=a_{M, \Delta t}+\beta_{M, \Delta t, 1} z_{1, t}+\beta_{M, \Delta t, 2} z_{2, t}+v_{M, t, t+\Delta t}, \\
r_{B, t, t+\Delta t}-\int_{t}^{t+\Delta t} r_{s} d s=a_{B, \Delta t}+\beta_{B, \Delta t, 1} z_{1, t}+\beta_{B, \Delta t, 2} z_{2, t}+v_{B, t, t+\Delta t},
\end{gathered}
$$

where $r_{M, t, t+\Delta t}$ (resp., $r_{B, t, t+\Delta t}$ ) is the one-period return on the stock market (resp., bond) between dates $t$ and $t+\Delta t$, the return on the stock possibly including a dividend.

Finally, we apply the same procedure to the interest rate, integrate the process $r_{t} e^{\theta_{r} t}$ over the time interval $[t, t+\Delta t]$ and identify the integrated process parameters with those of the discrete time regression, as we did for the predictors.

\subsection{Long horizon predictability}

To study the properties of the return generating processes implied by LHP, two approaches can be distinguished. The first, adopted by the strand of literature devoted to asset allocation, consists in mechanically inferring long horizon processes from the short term process by simple recursion. Consequently, no additional information can be gained by varying the prediction horizon. In contrast, the second approach, encountered in the literature devoted to inference problems associated with LHP, consists in using truly observed long horizon returns, which generally imply short period return dynamics completely different from the explicit one (see for instance Valkanov (2003), Bandi and Perron (2008) and Cochrane (2005)). As this procedure captures the information contained in actual returns, the estimated parameters and, consequently, the investor's strategy and welfare will in general depend on the prediction horizon. We borrow from this strand of research, without claiming originality, and fill a gap in the asset allocation literature by using the true, as opposed to inferred, long horizon returns.

To illustrate, suppose we have calibrated Eq. (14) and are now interested by a prediction horizon longer than one period $(h \geq 2 \Delta t)$. From forward recursion of Eq. (14), we obtain:

$$
\begin{aligned}
r_{M, t, t+h}-\int_{t}^{t+h} r_{s} d s= & \frac{h}{\Delta t} \cdot a_{M, \Delta t}+\beta_{M, \Delta t, 1} \sum_{j=0}^{h / \Delta t-1} z_{1, t+j \Delta t} \\
& +\beta_{M, \Delta t, 2} \sum_{j=0}^{h / \Delta t-1} z_{2, t+j \Delta t}+\sum_{j=1}^{h / \Delta t} \varepsilon_{M, t+(j-1) \Delta t, t+j \Delta t},
\end{aligned}
$$

where, crucially, the coefficients present in Eq. (16) are mere known, deterministic functions of those obtained for the one-period horizon $\Delta t$. 
Next, by forward recursion of Eqs. (13), Eq. (16) rewrites as:

$$
\begin{aligned}
r_{M, t, t+h}-\int_{t}^{t+h} r_{s} d s= & \frac{h}{\Delta t} \cdot a_{M, \Delta t}+\sum_{i=1}^{2} a_{z_{i}, \Delta t} \beta_{M, \Delta t, i} \sum_{j=1}^{h / \Delta t-1}\left(\frac{h}{\Delta t}-j\right) A_{z_{i}, \Delta t}^{j-1} \\
& +\left(\sum_{i=1}^{2} \beta_{M, \Delta t, i}\left[\sum_{j=0}^{h / \Delta t-1} A_{z_{i}, \Delta t}^{j}\right]\right) z_{i, t}+\sum_{j=1}^{h / \Delta t} \varepsilon_{M, t+(j-1) \Delta t, t+j \Delta t} \\
& +\sum_{i=1}^{2} \beta_{M, \Delta t, i} \sum_{k=1}^{h / \Delta t-1} v_{z_{i}, t+(k-1) \Delta t, t+k \Delta t} \sum_{l=0}^{l} A_{z_{i}, \Delta t}^{l}
\end{aligned}
$$

The properties of any long horizon return (such as its conditional and unconditional variances) can be studied extensively from Eq. (17), as did for example Brennan and Xia (2010) and Campbell and Viceira (2005). Also, when the model is taken to the data, one just has to estimate, once and for all, the coefficients for $h=\Delta t$, and then to generate mechanically the coefficients for any prediction horizon $h$.

Our procedure is novel in portfolio allocation models and follows that found in the literature on LHP devoted to inference problems. The coefficients of the discrete processes assumed for the stock excess return

$$
r_{M, t, t+h}-\int_{t}^{t+h} r_{s} d s=a_{M, h}+\beta_{M, h, 1} z_{1, t}+\beta_{M, h, 2} z_{2, t}+v_{M, t, t+h}
$$

are estimated using, in particular, the true long horizon returns. This is also true for the predictor processes:

$$
z_{i, t+h}=a_{z_{i}, h}+A_{z_{i}, h} z_{i, t}+v_{z_{i}, t, t+h} \quad \forall i=1,2 .
$$

As the optimal strategy involves intertemporal hedging terms that protect the investor from unfavorable changes in the state variables, we need to estimate the correlations between the stock and bond excess returns with the contemporaneous innovations in the predictors. For instance, to obtain an estimate of the 2-year-ahead stock risk premium, one must use the 2-year-ahead estimates for the values of the predictors also. This is a key point. The regression coefficients and the constant in Eqs. (18) and (19) are indexed by $h$, as they now depend on $h$ for two reasons. The first is obvious as the terms in the l.h.s. refer to $h$-period returns. The second, much more important, is that the actual distributions of long horizon returns may well be different from that inferred from one-period returns, and differ across $h$.

This approach, although in line with the LHP literature, suffers from the persistence due to overlapping observations. This is unfortunately necessary to generate reasonable series of longhorizon returns. We will address this issue in Section 6 (see Eq.(26)). 


\subsection{Parameter estimation}

To take the model to the data, we first integrate the continuous time dynamics Eq. (6) over the discrete time interval $[t, t+h]$ and obtain:

$$
z_{i, t+h}=\bar{z}_{h, i}\left(1-e^{-\theta_{h, i} h}\right)+e^{-\theta_{h, i} h} z_{i, t}+\sigma_{h, z_{i}} e^{-\theta_{h, i}(t+h)} \int_{t}^{t+h} e^{\theta_{h, i} s} d Z_{z_{i}, s}, \quad \forall i=1,2
$$

Next we identify, for a given $h$, the integrated process parameters with those of the discrete time regressions given by Eqs. (19). As shown in the Internet Appendix, our procedure yields the following seven (annualized) parameters: $\theta_{1}, \theta_{2}, \bar{z}_{1}, \bar{z}_{2}, \sigma_{z_{1}}^{2}, \sigma_{z_{2}}^{2}$, and $\rho_{1,2}$ (all of which depend on $h$ in spite of the parsimonious notation adopted here). We apply the same procedure to the interest rate, integrate the process $r_{t} e^{\theta_{r} t}$ over the time interval $[t, t+h]$ and obtain:

$$
r_{t+h}=\bar{r}_{h}\left(1-e^{-\theta_{h, r} h}\right)+e^{-\theta_{h, r} h} r_{t}+\sigma_{h, r} e^{-\theta_{h, r}(t+h)} \int_{t}^{t+h} e^{\theta_{h, r} s} d Z_{r, s}
$$

Identifying the integrated process parameters with those of the discrete time regression

$$
r_{t+h}=a_{r, h}+A_{r, h} r_{t}+v_{r, t, t+h}
$$

yields, for a given $h$, the following five parameters: $\theta_{r}, \bar{r}, \sigma_{r}^{2}, \rho_{1, r}$ and $\rho_{2, r}$ (see Internet Appendix).

As to stock excess returns, we integrate the continuous time process Eq. (2), using Eq. (4), over the discrete interval $[t, t+h]$ for each prediction horizon $h$. We obtain (see Internet Appendix):

$$
\begin{aligned}
\ln M_{t+h}-\ln M_{t}-\int_{t}^{t+h} r_{s} d s & =\left(\mu_{h, M, 0}-\frac{\sigma_{h, M}^{2}}{2}\right) h \\
& +\mu_{h, M, 1}\left(h-\frac{1}{\theta_{h, 1}}\left(1-e^{-\theta_{h, 1} h}\right)\right) \bar{z}_{h, 1} \\
& +\mu_{h, M, 2}\left(h-\frac{1}{\theta_{h, 2}}\left(1-e^{-\theta_{h, 2} h}\right)\right) \bar{z}_{h, 2} \\
& -\mu_{h, M, 1} \frac{1}{\theta_{h, 1}}\left(e^{-\theta_{h, 1} h}-1\right) z_{1, t}-\mu_{h, M, 2} \frac{1}{\theta_{h, 2}}\left(e^{-\theta_{h, 2} h}-1\right) z_{2, t} \\
& +\int_{t}^{t+h} \sigma_{h, M} d Z_{M, s} \\
& +\mu_{h, M, 1} \frac{1}{\theta_{h, 1}} \sigma_{h, z_{1}} \int_{t}^{t+h}\left(1-e^{-\theta_{h, 1}(t+h)} e^{\theta_{h, 1} s}\right) d Z_{z_{1}, s} \\
& +\mu_{h, M, 2} \frac{1}{\theta_{h, 2}} \sigma_{h, z_{2}} \int_{t}^{t+h}\left(1-e^{-\theta_{h, 2}(t+h)} e^{\theta_{h, 2} s}\right) d Z_{z_{2}, s} .
\end{aligned}
$$

The stock excess return is affected by three sources of risk: its own idiosyncratic component and the two components associated with the variability in the predictors. Therefore, when the 
return period length $h$ increases, the (annualized) volatility of the stock excess return, which would remain constant by assumption in absence of predictors, may decline or increase depending on the signs and magnitudes of the parameters extracted from the data that characterize the predictive processes. $^{7}, 8$

The same technique is applied to the constant maturity bond excess returns and yields a similar expression for $\ln B_{t+h}-\ln B_{t}-\int_{t}^{t+h} r_{s} d s$.

We then identify the integrated process parameters with those of the discrete time regressions (see Eq. (18)):

$$
r_{M, t, t+h}-\int_{t}^{t+h} r_{s} d s\left(\equiv R_{t, t+h}^{M}\right)=a_{M, h}+\beta_{M, h, 1} z_{1, t}+\beta_{M, h, 2} z_{2, t}+v_{M, t, t+h},
$$

and

$$
r_{B, t, t+h}-\int_{t}^{t+h} r_{s} d s=a_{B, h}+\beta_{B, h, 1} z_{1, t}+\beta_{B, h, 2} z_{2, t}+v_{B, t, t+h}
$$

where $r_{M, t, t+h}$ (resp., $r_{B, t, t+h}$ ) is the continuously compounded $h$-period return on the stock market (resp., bond) between dates $t$ and $t+h$.

This procedure yields, for each prediction horizon $h$, the fifteen needed parameters (again, deleting here the explicit dependence on $h): \mu_{M, 0}, \mu_{M, 1}, \mu_{M, 2}, \sigma_{M}^{2}, \rho_{r, M} \sigma_{M} \sigma_{r}, \rho_{1, M} \sigma_{M} \sigma_{z_{1}}, \rho_{2, M} \sigma_{M} \sigma_{z_{2}}$ for the stock market, $\mu_{B, 0}, \mu_{B, 1}, \mu_{B, 2}, \sigma_{B}^{2}, \rho_{r, B} \sigma_{B} \sigma_{r}, \rho_{1, B} \sigma_{B} \sigma_{z_{1}}, \rho_{2, B} \sigma_{B} \sigma_{z_{2}}$ for the bond and $\rho_{B, M} \sigma_{M} \sigma_{B}$ for their direct correlation [see the Internet Appendix]. ${ }^{9}$

${ }^{7}$ Note that the continuous time parameters are always expressed on a yearly basis for consistency, irrespective of the length of the prediction horizon. For instance, the instantaneous stock return variances estimated using monthly returns $\left(\sigma_{\Delta t, M}^{2}\right)$ or biannual returns $\left(\sigma_{6 \Delta t, M}^{2}\right)$ are both annualized.

${ }^{8}$ The volatility of stock returns estimated (without correcting for various other uncertainties) over the long run is often reported to be smaller than in the short term because of the mean reversion induced by return predictability. This is true for both realized variance and variance conditioned on information relevant in forecasting returns. However, Pastor and Stambaugh (2012) also find that the positive effect of other components of long horizon predictive variance (such as estimation risk and uncertainty about current and future expected returns) outweighs that of mean reversion. Consequently, they argue that the stock market is in fact more volatile over longer horizons from an investor's viewpoint. Fama and French (2018) also find that uncertainty about expected returns can significantly impact uncertainty about long-run returns. Although we ignore these other components for simplicity, our model could theoretically allow for such an increase in long run volatility.

${ }^{9} \mathrm{~A}$ statistical issue associated with our estimates is the persistence of predictors, a phenomenon acknowledged in the literature and confirmed by our data in Section 4. Persistence would require a correction for the estimated parameters of the predictive regressions as for instance in Stambaugh (1999) and Amihud, Hurwich and Wang (2008). However, since no method is available for long horizons prediction and the correction is fairly weak (in particular when the dividend yield is a predictor) for $h=\Delta t$, we ignore this issue. 


\section{Data and Estimation}

\subsection{Data}

This study uses US monthly data for the period 1942:M1 to 2016:M12 (900 observations). ${ }^{10}$ Data relative to the returns on the market portfolio have been downloaded from CRSP database. The stock market return ("mkt") is computed as the value-weighted return on all NYSE, AMEX, and NASDAQ stocks obtained from the CRSP data files. We have selected the constant 10-year maturity Treasury bond as our long term fixed income instrument. ${ }^{11}$ Its monthly returns ("bond") were downloaded from the CRSP files. The riskless rate is the one-month Treasury bill rate ("r") downloaded from the CRSP "Fama Risk Free Rates" data file.

The choice of predictors is more arbitrary, and many candidates have been proposed in the literature. As an illustration, we adopt the dividend yield and the default spread that are variously but routinely used since the early start of Fama and French (1989). ${ }^{12}$ The dividend yield ("dy") is measured as the total dividends paid off during the last 12 months divided by the actual value of the value-weighted market portfolio. We select this measure as monthly or quarterly dividend yields cannot be used because seasonality is predominant. We construct the dividend yield series from the two series of stock market returns with and without dividends. The default spread, a measure of financial duress, is computed as the spread between the yield of a 10-year Baa-rated bond and that of a 10-year Aaa-rated bond ("def"). This predictor is constructed from the relevant series in FRED ${ }^{\circledR}$ database. Summary statistics are reported in Table 1.

Panel A of Table 1 reports statistics for the one-month T-bill rate, the returns and excess returns (using the T-bill rate) on the risky assets and the predictors. The average excess return is $0.60 \%$ for the equity market ( $7.2 \%$ per year) and $0.13 \%$ for the long term bond (1.56\% annually). The average annualized short term rate is $3.73 \%$, which can be used as a benchmark. A salient feature of particular relevance emerges. The large first-order auto-regression coefficients for the predictive variables and the interest rate, ranging from 0.97 to 0.99 , reflect a high level of persistence, also found in the literature, to be discussed below. In contrast, the coefficients for the stock and bond are very small (0.09 for $m k t$ and 0.06 for bond). As shown in Panel B, the correlation of $d y$ with

\footnotetext{
${ }^{10} 1942$ :M1 is the first date for which returns on constant maturity bonds are available.

${ }^{11}$ The 10-year rate seems to be the usual long term reference. Results for predictive regressions are not significantly different with bonds of constant 20-year and 30-year maturities.

${ }^{12}$ The literature is abundant on this topic. For example, the term spread (Morell 2018), the consumptionwealth ratio (Lettau and Ludvigson 2001), the firms' total payout (Lamont 1998; Baker and Wurgler 2000), market volatility (Bandi et al. 2018) and option-implied expected returns (Martin 2017), among other variables, were also shown to have predictive ability. Goyal and Welch (2008) provided a comprehensive analysis of predictability for a variety of predictors at the monthly, quarterly, and annual frequencies and found a substantial heterogeneity in their explanatory power. See also Bianchi and Tamoni (2017) and Bandi et al. (2018) for a related discussion. As a robustness check, we redid the whole exercise of this paper with another pair of predictors, market volatility and term spread. One constraint was to retain the monthly frequency, and some predictors are computed at a quarterly frequency only, such as the consumption-to-wealth ratio. Results are reported in the Internet Appendix. We were heartened to find, qualitatively, almost the same patterns as with the dividend yield and default spread. This is not to deny that, quantitatively, the value added by LHP depends on the set of adopted predictors.
} 


\section{Table 1: Summary Statistics}

Panel A reports various statistics for the monthly returns on the stock market portfolio ( $m k t)$ and the 10-year bond (bond), and their monthly excess returns (mktex and bondex). In Panel B, we report the summary statistics for the one-month T-bill rate $(r)$ and two predictors: the dividend yield $(d y)$ and the default spread (def). Auto stands for the first-order auto-regression coefficient. Panel C displays the means and standard deviations for the interest rate and the stock and bond excess returns across different holding periods. The data cover the period 1942:M1 to 2016:M12.

\begin{tabular}{lccccccc}
\multicolumn{3}{c}{ Panel A: Stock, Bond and Predictors } \\
& mkt & mkt $^{\text {ex }}$ & bond & bond $^{\text {ex }}$ & dy & r & def \\
\hline Mean & 0.91 & 0.60 & 0.43 & 0.13 & 3.37 & 3.73 & 0.94 \\
Std & 4.22 & 4.24 & 1.96 & 1.95 & 1.39 & 3.13 & 0.43 \\
Skewness & -0.78 & -0.80 & 0.42 & 0.22 & 0.69 & 1.05 & 1.84 \\
Kurtosis & 5.73 & 5.72 & 5.21 & 5.12 & 3.25 & 4.42 & 7.88 \\
Auto & 0.09 & 0.09 & 0.07 & 0.06 & 0.99 & 0.97 & 0.97
\end{tabular}

Panel B: Stock, Bond and Predictors Correlations

\begin{tabular}{lccccccc} 
& mkt & mkt $^{\text {ex }}$ & bond & bond $^{\text {ex }}$ & dy & $\mathbf{r}$ & def \\
\hline mkt & 1.00 & 1.00 & 0.08 & 0.08 & 0.10 & -0.05 & 0.05 \\
mkt $^{e x}$ & 1.00 & 1.00 & 0.07 & 0.08 & 0.09 & -0.11 & 0.03 \\
bond & 0.08 & 0.07 & 1.00 & 0.99 & 0.01 & 0.12 & 0.11 \\
bond $^{e x}$ & 0.08 & 0.08 & 0.99 & 1.00 & 0.00 & -0.01 & 0.07 \\
dy & 0.10 & 0.09 & 0.01 & 0.00 & 1.00 & 0.06 & 0.11 \\
$\mathbf{r}$ & -0.05 & -0.11 & 0.12 & -0.01 & 0.06 & 1.00 & 0.31 \\
def & 0.05 & 0.03 & 0.11 & 0.07 & 0.11 & 0.31 & 1.00
\end{tabular}

Panel C: Interest rate and excess returns (annualized, in \%) for various horizons $h$

\begin{tabular}{lcccccc} 
& $\mathbf{m e a n}(\mathbf{r})$ & $\mathbf{s t d}(\mathbf{r})$ & $\left.\mathbf{m e a n}_{(\mathbf{m k t}}{ }^{e x}\right)$ & $\mathbf{s t d}\left(\mathbf{m k t}^{e x}\right)$ & $\left.\mathbf{m e a n}_{\left(\mathbf{b o n d}^{e x}\right.}\right)$ & $\mathbf{s t d}_{\left(\mathbf{b o n d}^{e x}\right)}$ \\
\hline $\mathbf{1 m}$ & 3.62 & 2.97 & 7.25 & 14.69 & 1.56 & 6.76 \\
$\mathbf{3 m}$ & 3.63 & 2.94 & 7.30 & 15.48 & 1.56 & 6.94 \\
$\mathbf{6 m}$ & 3.64 & 2.92 & 7.32 & 16.12 & 1.57 & 6.94 \\
$\mathbf{1 y}$ & 3.66 & 2.88 & 7.24 & 16.40 & 1.57 & 6.99 \\
$\mathbf{2 y}$ & 3.70 & 2.82 & 6.98 & 15.75 & 1.59 & 6.78 \\
$\mathbf{3 y}$ & 3.75 & 2.74 & 6.88 & 15.02 & 1.58 & 6.64 \\
$\mathbf{4 y}$ & 3.80 & 2.67 & 6.77 & 14.46 & 1.55 & 6.75 \\
$\mathbf{5 y}$ & 3.85 & 2.61 & 6.65 & 14.46 & 1.54 & 6.89 \\
$\mathbf{6 y}$ & 3.90 & 2.55 & 6.57 & 14.31 & 1.53 & 6.87 \\
$\mathbf{7 y}$ & 3.96 & 2.50 & 6.51 & 14.32 & 1.52 & 6.99 \\
$\mathbf{8 y}$ & 4.01 & 2.45 & 6.46 & 14.66 & 0.82 & 6.24 \\
$\mathbf{9 y}$ & 4.06 & 2.40 & 6.36 & 15.04 & 1.47 & 7.22 \\
$\mathbf{1 0 y}$ & 4.12 & 2.35 & 6.30 & 15.22 & 0.91 & 6.50
\end{tabular}


def (0.11) and that of $d y$ with the interest rate (0.06) are encouragingly small. The correlation of the interest rate with def is understandably larger (0.31). Panel $\mathrm{C}$ of Table 1 reports the influence of the holding period horizon on the means and standard deviations of the interest rate and of the stock and bond excess returns. Interestingly, the mean of the short term rate slightly increases, and its unconditional volatility decreases with the horizon. Also, the volatility of the stock excess return exhibits an inverted U-shape with a peak at one year (16.40\% annualized). Under a pure random walk, this volatility would not depend on the horizon. The study by Poterba and Summers (1988) covering the 1871-1985 period and the update by Brennan and Xia (2010) for the 1871-2003 period both report a similar peak, although at 2 years.

\subsection{Parameter estimates}

We estimate the parameters of the discretized continuous processes followed by the two predictors and the short term rate using the procedure described in Section 3 and detailed in the Internet Appendix. We also estimate the parameters for the stock and bond return processes and compute the corresponding Sharpe ratios. Findings are reported in Table 2.

In Panel A of Table 2 we check how the speed of mean reversion, the long run mean and the volatility characterizing the $\mathrm{O}-\mathrm{U}$ processes followed by the short term rate, Eq. (1), and the predictors, Eqs. (6), behave across prediction horizons. The decreasing patterns for volatilities and the speed of mean reversion are as expected. Time aggregation increases the signal-to-noise ratio and hence reduces the volatility. The mean reversion coefficients exhibit a (non monotonic) decreasing pattern according to $h$. Crucially, however, it is the product $\theta h$ that matters, as evidenced by Eq. (20). And this product does increase with $h$ even when $\theta$ decreases. This result is important as a larger $\theta h$ implies a lower persistence (see the Internet Appendix). Therefore, persistence is smaller for longer prediction horizons. Also, estimated long run values of both predictors are very stable across the board. As to the correlations between predictors, also displayed in Panel A, they increase swiftly reflecting again less noise and idiosyncratic variations for longer horizons. A high default spread signals economic duress which increases the riskless rate, depresses stock prices and thereby increases the dividend yield. Hence, the correlations are all positive in the long run.

Panel B of Table 2 displays the estimated parameters of the process followed by the stock excess return predicted by $d y$ and def. The annualized long run equity excess return $(E P)$ implied by our estimates is computed as the sum $\mu_{M, 0}+\mu_{M, 1} \bar{z}_{1}+\mu_{M, 2} \bar{z}_{2}$. EP is estimated to be $6.46 \%$ at the monthly frequency and $5.63 \%$ at the 10 -year frequency, the fall not being monotonic. Volatility slightly increases (not monotonically) from $14.70 \%$ to $15.30 \%$. The Sharpe ratio remains rather stable (at 0.43 ) up to $h=6$ years, then declines slowly and slightly to 0.37 . The correlation of the market with the dividend yield is pretty stable at the usual level (between -0.68 and -0.87) while those with the interest rate and the default spread stabilize at around -0.5 for long horizons. The 
Table 2: Parameters Estimates

Panel A of this Table reports the estimated parameters of the processes followed by the predictors $d y$ and def and the interest rate $r$. The estimated parameters of the processes followed by the equity market return and the 10-year bond return are reported in Panels B and C, respectively. Also on display are the long-run equity excess return (EP) and 10-year bond excess return (BP), and their corresponding Sharpe Ratios $(S R)$. The sample period is 1942:M1 to 2016:M12.

Panel A: Parameters for the predictors and the interest rate

\begin{tabular}{|c|c|c|c|c|c|c|c|c|c|c|c|c|c|c|}
\hline & & $1 \mathrm{~m}$ & $3 \mathrm{~m}$ & $6 \mathrm{~m}$ & $1 y$ & $2 y$ & $3 y$ & $4 y$ & $5 y$ & $6 y$ & $7 y$ & $8 \mathbf{y}$ & $9 y$ & $10 y$ \\
\hline \multirow[t]{3}{*}{$r$} & $\theta$ & 0.36 & 0.21 & 0.17 & 0.15 & 0.15 & 0.14 & 0.12 & 0.10 & 0.09 & 0.09 & 0.09 & 0.10 & 0.09 \\
\hline & LR Mean (\%) & 3.77 & 3.80 & 3.82 & 3.82 & 3.84 & 3.88 & 3.92 & 3.96 & 4.00 & 4.04 & 4.07 & 4.11 & 4.15 \\
\hline & $\sigma(\%)$ & 2.63 & 2.00 & 1.82 & 1.69 & 1.72 & 1.66 & 1.54 & 1.38 & 1.32 & 1.33 & 1.34 & 1.36 & 1.34 \\
\hline \multirow[t]{3}{*}{$d y$} & $\theta$ & 0.14 & 0.16 & 0.18 & 0.18 & 0.13 & 0.12 & 0.10 & 0.09 & 0.09 & 0.08 & 0.09 & 0.10 & 0.11 \\
\hline & LR Mean (\%) & 2.83 & 2.86 & 2.91 & 2.94 & 2.91 & 2.89 & 2.88 & 2.88 & 2.85 & 2.78 & 2.76 & 2.76 & 2.77 \\
\hline & $\sigma(\%)$ & 0.57 & 0.59 & 0.64 & 0.66 & 0.60 & 0.57 & 0.55 & 0.53 & 0.52 & 0.49 & 0.48 & 0.48 & 0.49 \\
\hline \multirow[t]{6}{*}{$\operatorname{def}$} & $\theta$ & 0.34 & 0.49 & 0.55 & 0.58 & 0.51 & 0.39 & 0.33 & 0.28 & 0.23 & 0.21 & 0.33 & 0.35 & 0.30 \\
\hline & LR Mean (\%) & 0.92 & 0.92 & 0.93 & 0.93 & 0.93 & 0.93 & 0.94 & 0.94 & 0.95 & 0.96 & 0.96 & 0.96 & 0.97 \\
\hline & $\sigma(\%)$ & 0.35 & 0.42 & 0.44 & 0.46 & 0.43 & 0.38 & 0.35 & 0.32 & 0.29 & 0.28 & 0.36 & 0.37 & 0.34 \\
\hline & $\operatorname{corr}(\mathbf{r}, \mathrm{dy})$ & -0.01 & 0.02 & 0.05 & 0.06 & 0.17 & 0.21 & 0.23 & 0.28 & 0.31 & 0.35 & 0.41 & 0.45 & 0.51 \\
\hline & $\operatorname{corr}(r$, def $)$ & -0.25 & -0.26 & -0.24 & -0.26 & -0.11 & 0.05 & 0.16 & 0.19 & 0.19 & 0.21 & 0.22 & 0.24 & 0.27 \\
\hline & $\operatorname{corr}(\mathrm{def}, \mathrm{dy})$ & 0.04 & 0.18 & 0.30 & 0.32 & 0.32 & 0.30 & 0.30 & 0.28 & 0.28 & 0.31 & 0.38 & 0.44 & 0.45 \\
\hline
\end{tabular}

Panel B: Parameters for the stock market

\begin{tabular}{lcccccccccccccc} 
& $\mathbf{1 m}$ & $\mathbf{3 m}$ & $\mathbf{6 m}$ & $\mathbf{1 y}$ & $\mathbf{2 y}$ & $\mathbf{3 y}$ & $\mathbf{4 y}$ & $\mathbf{5 y}$ & $\mathbf{6 y}$ & $\mathbf{7 y}$ & $\mathbf{8 y}$ & $\mathbf{9 y}$ & $\mathbf{1 0 y}$ \\
\hline$\mu_{0}$ & -0.061 & -0.079 & -0.107 & -0.102 & -0.061 & -0.045 & -0.041 & -0.045 & -0.041 & -0.037 & -0.035 & -0.034 & -0.048 \\
$\mu_{1}$ & 3.499 & 3.875 & 4.277 & 4.445 & 3.881 & 3.611 & 3.346 & 3.233 & 3.326 & 3.368 & 3.604 & 3.782 & 3.990 \\
$\mu_{2}$ & 2.632 & 3.387 & 5.072 & 3.972 & 1.388 & 0.397 & 0.620 & 1.308 & 0.488 & -0.225 & -1.155 & -1.755 & -0.812 \\
$\mathbf{L R}$ Mean = EP & 0.064 & 0.065 & 0.066 & 0.068 & 0.066 & 0.064 & 0.062 & 0.061 & 0.059 & 0.055 & 0.054 & 0.054 & 0.056 \\
$\sigma$ & 0.148 & 0.156 & 0.164 & 0.168 & 0.161 & 0.151 & 0.143 & 0.144 & 0.140 & 0.138 & 0.137 & 0.143 & 0.154 \\
$S R$ & 0.430 & 0.414 & 0.406 & 0.401 & 0.409 & 0.425 & 0.435 & 0.425 & 0.418 & 0.402 & 0.394 & 0.376 & 0.362 \\
corr(r,mkt) & 0.019 & 0.027 & 0.017 & 0.041 & -0.012 & -0.035 & -0.078 & -0.166 & -0.289 & -0.396 & -0.483 & -0.518 & -0.558 \\
corr(dy,mkt) & -0.872 & -0.871 & -0.844 & -0.809 & -0.762 & -0.717 & -0.686 & -0.701 & -0.747 & -0.785 & -0.814 & -0.842 & -0.848 \\
corr(def,mkt) & -0.082 & -0.278 & -0.453 & -0.521 & -0.541 & -0.518 & -0.515 & -0.493 & -0.440 & -0.466 & -0.507 & -0.545 & -0.571
\end{tabular}

Panel C: Parameters for the 10-year bond

\begin{tabular}{lcccccccccccccc} 
& $\mathbf{1 m}$ & $\mathbf{3 m}$ & $\mathbf{6 m}$ & $\mathbf{1 y}$ & $\mathbf{2 y}$ & $\mathbf{3 y}$ & $\mathbf{4 y}$ & $\mathbf{5 y}$ & $\mathbf{6 y}$ & $\mathbf{7 y}$ & $\mathbf{8 y}$ & $\mathbf{9 y}$ & $\mathbf{1 0 y}$ \\
\hline$\mu_{0}$ & 0.006 & 0.027 & 0.031 & 0.027 & 0.009 & -0.011 & -0.014 & -0.005 & -0.006 & -0.008 & -0.021 & -0.040 & -0.041 \\
$\mu_{1}$ & -0.439 & -0.707 & -0.933 & -1.109 & -1.261 & -1.199 & -1.187 & -1.220 & -1.251 & -1.172 & -1.031 & -1.314 & -1.261 \\
$\mu_{2}$ & 3.329 & 2.104 & 2.508 & 3.596 & 6.028 & 7.902 & 8.121 & 7.222 & 7.367 & 7.323 & 7.351 & 11.171 & 10.370 \\
LR Mean = BP & 0.024 & 0.026 & 0.027 & 0.028 & 0.028 & 0.028 & 0.028 & 0.029 & 0.029 & 0.029 & 0.021 & 0.032 & 0.025 & 0.025 \\
$\sigma$ & 0.089 & 0.090 & 0.088 & 0.087 & 0.086 & 0.090 & 0.095 & 0.095 & 0.095 & 0.098 & 0.094 & 0.117 & 0.112 \\
$S R$ & 0.271 & 0.291 & 0.310 & 0.316 & 0.326 & 0.307 & 0.294 & 0.300 & 0.304 & 0.300 & 0.222 & 0.276 & 0.224 \\
corr(r,bond) & -0.208 & -0.386 & -0.447 & -0.501 & -0.602 & -0.605 & -0.640 & -0.676 & -0.688 & -0.705 & -0.742 & -0.712 & -0.684 \\
corr(dy,bond) & -0.129 & -0.103 & -0.094 & -0.183 & -0.283 & -0.309 & -0.301 & -0.283 & -0.330 & -0.419 & -0.499 & -0.587 & -0.597 \\
corr(def,bond) & 0.229 & 0.307 & 0.214 & 0.062 & -0.255 & -0.565 & -0.652 & -0.608 & -0.661 & -0.700 & -0.697 & -0.799 & -0.825 \\
corr(mkt,bond) & 0.078 & 0.036 & 0.040 & 0.176 & 0.339 & 0.433 & 0.451 & 0.442 & 0.506 & 0.584 & 0.673 & 0.760 & 0.754
\end{tabular}


negative signs were expected: when the interest rate decreases, investors reallocate their portfolios towards stocks, exerting an upward pressure on prices leading to positive future returns. An increasing default spread reflects economic dire straights which press stock prices downward.

From Panel C of Table 2 no clear picture emerges as to the long run excess return on the 10-year bond which varies somewhat erratically but in a rather narrow range. Its volatility is pretty stable (around 6.7\%) except for a noticeable increase for $h=9$ and 10 years, as well as its Sharpe ratio. Overall, the choice of the prediction horizon $h$ affects the estimated values of the parameters of the stock and bond excess return processes. ${ }^{13}$

\subsection{Simulating parameter estimates}

The point-wise estimation proposed above might not help assessing whether estimates are biased at particular (long) horizons. To address this issue, we ran simulations the purpose of which is to shed light on the estimation risk and its impact on the findings, in particular the parameters for the stock and bond excess returns and the CE spreads in sample. We thus provide a reasonable range for the values of the parameters and variables of interest. One problem in the simulations is to preserve accurately enough the observed time series cross correlation between these variables. For brevity, we only sketch here the main steps of the method and relegate detailed procedure and results to the Internet Appendix (Sections 2.4 and 2.5).

For the two predictors and the interest rate, we ran an OLS AR(1) process and collected the residuals. We then ran a bivariate predictive regression for both the market and bond excess returns and collected the residuals. Consequently, we obtained a $T \times K$ matrix of residuals, where $T=900$ (observations) and $K=5$ (residuals). Then, using these time series residuals, we simulated 1,000 samples of the same size as our data (900 observations) using a multivariate normal distribution with mean 0 and a variance-covariance matrix identical to that of the residuals. Using the simulated residuals, we built time series for the two predictors, the interest rate and the two asset excess returns. For each simulation, we ran OLS estimations for the AR(1) processes and the stock and bond excess return predictive regressions. Doing this 1,000 times, we obtained 1,000 estimates for each desired parameter. The estimates for the parameter means are very stable across the board (i.e. for all the parameters at all prediction horizons) and the OLS and NW t-stats are very high and roughly equal. We also redid the whole exercise to account for the problem of overlapping data using Valkanov's (2003) procedure (see Section 6 below for a discussion), which yielded even more stable estimates.

Even though the point-estimated values of our parameters may be different from their respective simulated means, they lie well in the range of their simulated values. Thus the upshot of the analysis

\footnotetext{
${ }^{13}$ We have, additionally, checked that estimating separately the parameters of the predictive regressions and of the excess return dynamics for each prediction horizon rather than mechanically inferring them from those obtained from the one-period horizon does lead to statistically significant differences. Our approach and detailed results are discussed in the Internet Appendix.
} 
is that, although we do not claim that the in-sample evidence is indisputable, our parameters appear to be well estimated and not to suffer from biases at any estimation horizon.

\section{$5 \quad$ Asset allocation strategies}

\subsection{Certainty equivalent rates of return}

Endowed with our estimated parameters, we can implement the investor's portfolio strategies. We compute by way of Eq. (9) the optimal portfolio composition, which includes the meanvariance term $M V$ and the intertemporal hedging components $I H$. Using Eq. (10), we calculate the annualized certainty equivalent rate of return of the optimal strategy, $C E_{\text {opt }}$, which can be compared to the average riskless rate, $3.73 \%$. Similarly, we compute $C E_{m y o}$ associated with the myopic allocation. We set the individual's risk aversion coefficient $\gamma$ to 5 , a reasonable value likely to generate significant intertemporal hedging demands.

We consider many different situations by varying the investment horizon $T$ and the prediction horizon $h$. In papers devoted to portfolio allocation, the prediction horizon is usually one month, more rarely one quarter. This is not necessarily optimal. A long term investor should use short horizon predictability if the latter is more valuable than LHP. Likewise, a short term investor should exploit LHP if it is welfare improving. We use for $h$ the same values as in the predictive regressions, from one month to ten years, and for $T$ a wider range that includes four additional horizons, namely 15, 20, 25 and 30 years (we have, however, omitted to report the 2-, 4-, 6- and 8 -year horizons for readability). This yields a computed $(13 \times 17)$ matrix and a reported $(13 \times 13)$ matrix of optimal CE return rates. ${ }^{14}$ Results are displayed in Table 3.

Two strong general patterns emerge. The first was expected: for a given prediction horizon, the annualized $C E_{\text {opt }}$ return rate increases sharply and monotonically with the investment period. For the 30-year horizon, $C E_{\text {opt }}$ is approximately 1.5 to 3.5 times as large as it is for the one-month horizon, depending on the prediction horizon. According to the professional conventional wisdom in asset allocation, the weight of risky assets in the optimal portfolio should depend positively on the investment's horizon. As shown below, this is the case for all prediction horizons. The sharp increase in the proportion of risky assets entails that of the certainty equivalent return rate, as the investor can benefit more from the positive stock and bond risk premia. $C E_{\text {opt }}$ is across the board well above the average riskless rate $(3.73 \%)$ because the weight of the global risky position in the portfolio entails most of the time some leverage. Our results confirm those of Brennan and Xia (2010) based on scenarios and simulations.

Reading Table 3 column-wise, the second, and more crucial to our investigation, striking pattern is the rather strong tendency for $C E_{\text {opt }}$ to increase with the prediction horizon, for investment horizons beyond 1 year. For instance, for $T=1,10$ and 30 years, respectively, $C E_{\text {opt }}$ is equal

\footnotetext{
${ }^{14}$ The omitted results are available upon request.
} 


\section{Table 3: Certainty Equivalent Rates}

This Table reports annualized CE rates (in \%) for optimal strategies when the stock and 10-year bond excess returns (computed over 1 month up to 10 years) are predicted as in Table 2. The investment horizon $T$ ranges (horizontally) from one month to 30 years. The prediction horizon $h$ ranges (vertically) from one month to 10 years. The average riskless rate is 3.73\%. The period is 1942:M1 to 2016:M12.

\begin{tabular}{lccccccccccccc} 
& $\mathbf{1 m}$ & $\mathbf{3 m}$ & $\mathbf{6 m}$ & $\mathbf{1 y}$ & $\mathbf{3 y}$ & $\mathbf{5 y}$ & $\mathbf{7 y}$ & $\mathbf{9 y}$ & $\mathbf{1 0 y}$ & $\mathbf{1 5 y}$ & $\mathbf{2 0 y}$ & $\mathbf{2 5 y}$ & $\mathbf{3 0 y}$ \\
\hline $\mathbf{1 m}$ & 6.24 & 6.31 & 6.42 & 6.61 & 7.13 & 7.49 & 7.79 & 8.05 & 8.16 & 8.63 & 8.95 & 9.17 & 9.33 \\
$\mathbf{3 m}$ & 6.27 & 6.36 & 6.49 & 6.71 & 7.36 & 7.80 & 8.13 & 8.39 & 8.50 & 8.90 & 9.15 & 9.31 & 9.43 \\
$\mathbf{6 m}$ & 6.29 & 6.41 & 6.58 & 6.88 & 7.76 & 8.35 & 8.76 & 9.05 & 9.17 & 9.55 & 9.74 & 9.84 & 9.91 \\
$\mathbf{1 y}$ & 6.10 & 6.24 & 6.43 & 6.77 & 7.72 & 8.34 & 8.76 & 9.06 & 9.17 & 9.52 & 9.68 & 9.76 & 9.80 \\
$\mathbf{2 y}$ & 6.10 & 6.29 & 6.55 & 6.99 & 8.11 & 8.75 & 9.17 & 9.47 & 9.59 & 9.96 & 10.15 & 10.26 & 10.33 \\
$\mathbf{3 y}$ & 6.17 & 6.38 & 6.67 & 7.20 & 8.67 & 9.53 & 10.06 & 10.42 & 10.56 & 10.98 & 11.17 & 11.28 & 11.34 \\
$\mathbf{4 y}$ & 6.20 & 6.38 & 6.64 & 7.12 & 8.59 & 9.52 & 10.13 & 10.54 & 10.69 & 11.15 & 11.34 & 11.42 & 11.46 \\
$\mathbf{5 y}$ & 6.17 & 6.31 & 6.52 & 6.91 & 8.18 & 9.04 & 9.63 & 10.04 & 10.20 & 10.67 & 10.84 & 10.90 & 10.90 \\
$\mathbf{6 y}$ & 6.16 & 6.30 & 6.50 & 6.90 & 8.24 & 9.25 & 9.99 & 10.54 & 10.76 & 11.48 & 11.83 & 12.00 & 12.07 \\
$\mathbf{7 y}$ & 5.98 & 6.11 & 6.31 & 6.70 & 8.06 & 9.12 & 9.92 & 10.54 & 10.79 & 11.66 & 12.14 & 12.41 & 12.56 \\
$\mathbf{8 y}$ & 5.70 & 5.92 & 6.23 & 6.80 & 8.56 & 9.71 & 10.49 & 11.05 & 11.28 & 12.03 & 12.42 & 12.63 & 12.74 \\
$\mathbf{9 y}$ & 5.74 & 6.21 & 6.89 & 8.21 & 12.35 & 14.80 & 16.27 & 17.25 & 17.62 & 18.85 & 19.50 & 19.87 & 20.10 \\
$\mathbf{1 0 y}$ & 5.70 & 6.04 & 6.55 & 7.54 & 11.03 & 13.51 & 15.16 & 16.29 & 16.72 & 18.12 & 18.85 & 19.26 & 19.51
\end{tabular}

to $6.61 \%, 8.16 \%$ and $9.33 \%$ when $h$ is one month, and to $7.54 \%, 16.72 \%$ and $19.51 \%$ when $h$ is ten years. This novel result is consistent with the academic conventional wisdom, in the sense that, since the $R^{2}$ s of the predictive regressions increase with $h$, one expects LHP to be valuable. Note however that the relationship is not monotonic and presents humps for some $(h, T)$ couples. $^{15}$ Therefore, caution is required here as there is no unique prediction horizon that would be optimal for all investors. Nonetheless, except for very short run investors, LHP improves welfare significantly. Recall that the Sharpe ratio for the stock market remains stable up to $h=6$ years, then declines slightly only, and is rather stable for the 10-year bond. In addition, the level of intertemporal hedging increases with $h$ as the (absolute value) of the correlations of the stock and the bond with the predictors and the interest rate rise sharply (see Table 2). This translates into more weights allocated to the risky assets, as shown below, and into a better risk-return tradeoff, which in turn improves the optimal certainty equivalent rates.

It would be helpful to provide a theoretical justification regarding the relationship between $\mathrm{CE}$ rates and R-squares for a better understanding of our empirical results. Cochrane (1999) uses Hansen-Jagannathan (1991) bounds to derive a relationship between the maximum unconditional Sharpe ratio attainable using a univariate predictive regression and the regression $R^{2}{ }^{16}$ Cochrane's

\footnotetext{
${ }^{15}$ Bandi et al. (2018), among others, also find a hump-shaped relationship, with the hump showing up for $h$ between 11 and 16 years, i.e. beyond our range of 10 years. Since they use the past market variance as a unique predictor, their result is not directly comparable to ours.

${ }^{16} \mathrm{We}$ are grateful to an anonymous referee for having pointed this out.
} 
purpose was to assess the economic importance of $R^{2}$ improvement without having to compute the portfolio strategy or, equivalently, the associated CE rate. For general risk preferences and multivariate predictive regressions, unfortunately, we could not derive a Cochrane-like analytical result due to the presence of intertemporal hedging. As a substitute, we conducted a two-step numerical investigation of the relationship. ${ }^{17}$ First, we established the link between the predictive $R^{2}$ for the market and the bond returns as a function of the prediction horizon. Although, as already reported, the relationship is not monotonically increasing, it is nevertheless very close to being a straight line for the equity market, except for a prediction horizon larger than 9 years. For the bond, it is hump-shaped, the increase being monotonic up to $h$ equal to 4 years.

Next we assessed the relationship between CE rates and $R^{2}$ s. For investment horizons larger than one year, and for both the market and the bond, CE rates increase with the predictive $R^{2}$ s, which is consistent with Cochrane's (1999) result that the maximum Sharpe ratio increases with the predictive $R^{2}$. Therefore, it is fair to conclude that the better goodness-of-fit obtained by increasing the prediction horizon (up to 9 years for our sample) is economically relevant, at least for investment horizons larger than one year.

\subsection{Simulated Certainty Equivalent spreads}

As we did for the parameter estimation, we simulated the CE rates (1,000 times) to assess whether investors should focus on particular prediction horizons. To gain insight, we computed the spreads between the CE rate for a given prediction horizon and that for the one-month prediction horizon. ${ }^{18}$ Panel A of Table 4 displays the mean of these spreads. The investment horizon ranges from one month to 30 years and the prediction horizon from 3 month to 10 years. Panel B reports the Newey-West t-stats relative to the means. To gain space, OLS t-stats are not shown as they are almost identical to Newey-West ones. With rare exceptions, both t-stats are very large.

In Panel A, we observe first a systematic increase in CE spreads with the investment horizon, as expected. The relative imprecision in the parameter estimates does not translate into very volatile $\mathrm{CE}$ rates and spreads. Second, the relationship between the CE spread and the prediction horizon exhibits a substantial positive slope for all investment horizons beyond one year and, although not monotonic, is globally positive for investment horizons up to one year. Overall, the picture obtained for CE rates thus is confirmed. The potential welfare gain from LHP may be substantial for medium and long horizon investors. Increased uncertainty on the parameter estimates is more than compensated by positively skewed welfare gains.

Finally, the last row of Panel $\mathrm{C}$ in Table 2 has shown that the correlation between market and bond excess returns increases with the prediction horizon from negligible levels to 0.76. One may wonder whether portfolio allocations, hence CE rates, are driven by this finding rather than by

\footnotetext{
${ }^{17}$ Results are available upon request to the authors.

${ }^{18}$ The Internet Appendix provides the $\mathrm{CE}$ rates from which spreads are obtained.
} 


\section{Table 4: Simulated Certainty Equivalent Spreads}

This Table reports the simulated annualized CE spreads (in \%) for optimal strategies when the stock and 10-year bond excess returns are simulated 1,000 times. The investment horizon $T$ ranges (vertically) from one month to 30 years. The prediction horizon $h$ ranges (horizontally) from 3 month to 10 years, and the spread is computed relative to the one-month prediction period. Panel A displays the mean spreads (computed over the 1,000 simulations). Panel B exhibits the Newey-West t-stats relative to these means, the number of lags being equal to the estimation horizon minus 1. The sample period is 1942:M1 to 2016:M12.

\section{Panel A: Mean Spreads}

\begin{tabular}{|c|c|c|c|c|c|c|c|c|c|c|c|c|c|}
\hline & $1 \mathrm{~m}$ & $3 \mathrm{~m}$ & $6 \mathrm{~m}$ & $1 y$ & $2 y$ & $3 y$ & $4 y$ & $5 y$ & $6 y$ & $7 y$ & $8 y$ & $9 y$ & $10 y$ \\
\hline $1 \mathrm{~m}$ & & -0.03 & -0.06 & -0.12 & -0.15 & -0.14 & -0.10 & -0.03 & 0.03 & 0.16 & 0.10 & 0.48 & 0.46 \\
\hline $3 m$ & & -0.02 & -0.05 & -0.10 & -0.13 & -0.11 & -0.05 & 0.01 & 0.09 & 0.21 & 0.14 & 0.53 & 0.53 \\
\hline $6 \mathrm{~m}$ & & -0.01 & -0.04 & -0.08 & -0.10 & -0.05 & 0.01 & 0.09 & 0.17 & 0.29 & 0.21 & 0.62 & 0.66 \\
\hline $1 y$ & & 0.01 & -0.01 & -0.04 & -0.03 & 0.04 & 0.12 & 0.21 & 0.31 & 0.44 & 0.35 & 0.79 & 0.88 \\
\hline $3 y$ & & 0.05 & 0.07 & 0.08 & 0.17 & 0.33 & 0.50 & 0.64 & 0.82 & 0.97 & 0.89 & 1.45 & 1.76 \\
\hline $5 y$ & & 0.08 & 0.11 & 0.15 & 0.29 & 0.50 & 0.71 & 0.91 & 1.13 & 1.31 & 1.28 & 1.91 & 2.45 \\
\hline $7 y$ & & 0.08 & 0.12 & 0.18 & 0.35 & 0.60 & 0.84 & 1.05 & 1.30 & 1.52 & 1.54 & 2.22 & 2.85 \\
\hline $10 y$ & & 0.07 & 0.12 & 0.19 & 0.38 & 0.66 & 0.93 & 1.16 & 1.44 & 1.68 & 1.74 & 2.44 & 3.15 \\
\hline $15 y$ & & 0.05 & 0.10 & 0.18 & 0.38 & 0.67 & 0.95 & 1.19 & 1.49 & 1.74 & 1.83 & 2.53 & 3.33 \\
\hline $20 y$ & & 0.03 & 0.07 & 0.15 & 0.36 & 0.65 & 0.93 & 1.17 & 1.46 & 1.72 & 1.83 & 2.52 & 3.35 \\
\hline $25 y$ & & 0.01 & 0.05 & 0.12 & 0.34 & 0.63 & 0.91 & 1.15 & 1.42 & 1.68 & 1.79 & 2.48 & 3.33 \\
\hline $30 y$ & & -0.01 & 0.03 & 0.10 & 0.31 & 0.61 & 0.88 & 1.12 & 1.38 & 1.64 & 1.75 & 2.44 & 3.29 \\
\hline
\end{tabular}

Panel B: Newey - West $t$-Statistics

\begin{tabular}{|c|c|c|c|c|c|c|c|c|c|c|c|c|c|}
\hline & $1 \mathrm{~m}$ & $3 \mathrm{~m}$ & $6 \mathrm{~m}$ & $1 y$ & $2 y$ & $3 y$ & $4 y$ & $5 y$ & $6 y$ & $7 y$ & $8 y$ & $9 y$ & $10 y$ \\
\hline $1 \mathrm{~m}$ & & -5.1 & -7.1 & -8.5 & -7.2 & -5.1 & -3.2 & -0.9 & 0.8 & 2.8 & 1.6 & 6.8 & 7.4 \\
\hline $3 \mathrm{~m}$ & & -3.6 & -5.8 & -7.4 & -6.1 & -3.8 & -1.6 & 0.3 & 1.8 & 3.7 & 2.2 & 7.6 & 8.4 \\
\hline $6 \mathrm{~m}$ & & -2.0 & -4.0 & -5.8 & -4.4 & -1.8 & 0.2 & 2.2 & 3.4 & 4.9 & 3.2 & 8.6 & 10.5 \\
\hline $1 y$ & & 1.3 & -1.2 & -3.0 & -1.4 & 1.3 & 3.3 & 5.0 & 6.0 & 7.0 & 5.1 & 10.5 & 13.9 \\
\hline $3 y$ & & 8.8 & 6.8 & 5.4 & 7.3 & 9.8 & 11.4 & 13.1 & 13.4 & 13.4 & 11.1 & 16.6 & 28.2 \\
\hline $5 y$ & & 11.9 & 9.9 & 8.9 & 11.6 & 14.4 & 15.6 & 17.1 & 17.7 & 16.9 & 15.0 & 20.7 & 33.1 \\
\hline $7 y$ & & 11.2 & 10.2 & 10.1 & 13.6 & 16.7 & 17.6 & 19.3 & 20.0 & 18.8 & 17.2 & 22.4 & 32.8 \\
\hline $10 y$ & & 9.3 & 9.7 & 10.0 & 14.4 & 17.9 & 18.6 & 20.4 & 21.4 & 20.2 & 19.0 & 23.6 & 31.3 \\
\hline $15 y$ & & 5.7 & 7.3 & 8.4 & 13.8 & 18.0 & 18.5 & 20.2 & 21.4 & 20.7 & 20.0 & 23.7 & 28.9 \\
\hline $20 y$ & & 3.3 & 5.1 & 6.6 & 12.7 & 17.4 & 18.0 & 19.6 & 20.8 & 20.0 & 19.7 & 23.3 & 27.4 \\
\hline $25 y$ & & 1.1 & 3.5 & 5.4 & 11.7 & 16.7 & 17.3 & 18.9 & 20.0 & 19.5 & 19.3 & 22.8 & 26.4 \\
\hline $30 y$ & & -0.7 & 2.0 & 4.2 & 10.6 & 16.0 & 16.7 & 18.3 & 19.3 & 18.9 & 18.8 & 22.3 & 25.7 \\
\hline
\end{tabular}




\section{Table 5: Optimal Strategies}

This Table reports the overall weight of the risky assets (stocks and bonds) in the portfolio. Weights larger than one imply that the riskless asset is held negatively. The period is 1942:M1 to 2016:M12.

\begin{tabular}{lccccccccccccc} 
& $\mathbf{1 m}$ & $\mathbf{3 m}$ & $\mathbf{6 m}$ & $\mathbf{1 y}$ & $\mathbf{3 y}$ & $\mathbf{5 y}$ & $\mathbf{7 y}$ & $\mathbf{9 y}$ & $\mathbf{1 0 y}$ & $\mathbf{1 5 y}$ & $\mathbf{2 0 y}$ & $\mathbf{2 5 y}$ & $\mathbf{3 0 y}$ \\
\hline $\mathbf{1 m}$ & 1.24 & 1.25 & 1.28 & 1.32 & 1.47 & 1.60 & 1.71 & 1.81 & 1.86 & 2.04 & 2.17 & 2.25 & 2.30 \\
$\mathbf{3 m}$ & 1.27 & 1.29 & 1.32 & 1.37 & 1.59 & 1.78 & 1.93 & 2.05 & 2.11 & 2.30 & 2.42 & 2.48 & 2.52 \\
$\mathbf{6 m}$ & 1.28 & 1.31 & 1.34 & 1.42 & 1.68 & 1.90 & 2.08 & 2.22 & 2.28 & 2.47 & 2.57 & 2.62 & 2.64 \\
$\mathbf{1 y}$ & 1.17 & 1.19 & 1.23 & 1.31 & 1.59 & 1.81 & 1.99 & 2.13 & 2.19 & 2.37 & 2.46 & 2.50 & 2.52 \\
$\mathbf{2 y}$ & 1.16 & 1.19 & 1.25 & 1.35 & 1.69 & 1.95 & 2.15 & 2.30 & 2.37 & 2.57 & 2.67 & 2.72 & 2.74 \\
$\mathbf{3 y}$ & 1.11 & 1.15 & 1.21 & 1.34 & 1.78 & 2.13 & 2.39 & 2.59 & 2.67 & 2.95 & 3.10 & 3.17 & 3.20 \\
$\mathbf{4 y}$ & 1.05 & 1.09 & 1.15 & 1.28 & 1.74 & 2.13 & 2.45 & 2.69 & 2.80 & 3.17 & 3.37 & 3.47 & 3.53 \\
$\mathbf{5 y}$ & 1.05 & 1.09 & 1.15 & 1.26 & 1.71 & 2.09 & 2.41 & 2.67 & 2.79 & 3.22 & 3.48 & 3.63 & 3.72 \\
$\mathbf{6 y}$ & 1.05 & 1.09 & 1.14 & 1.25 & 1.68 & 2.06 & 2.40 & 2.70 & 2.83 & 3.34 & 3.67 & 3.88 & 4.01 \\
$\mathbf{7 y}$ & 0.95 & 0.98 & 1.03 & 1.13 & 1.52 & 1.89 & 2.22 & 2.51 & 2.64 & 3.18 & 3.54 & 3.78 & 3.94 \\
$\mathbf{8 y}$ & 0.43 & 0.46 & 0.49 & 0.57 & 0.93 & 1.27 & 1.59 & 1.87 & 1.99 & 2.49 & 2.80 & 3.00 & 3.12 \\
$\mathbf{9 y}$ & 0.54 & 0.56 & 0.60 & 0.70 & 1.16 & 1.58 & 1.93 & 2.22 & 2.36 & 2.87 & 3.20 & 3.40 & 3.53 \\
$\mathbf{1 0 y}$ & 0.38 & 0.39 & 0.41 & 0.46 & 0.73 & 1.06 & 1.38 & 1.66 & 1.79 & 2.32 & 2.66 & 2.88 & 3.01
\end{tabular}

predictability. Intuition suggests a negative answer, as the main driver of expected returns is more the risky/riskless asset mix than the stock/bond mix in the risky part (see Section 5.3 below). Simulating the stock/bond correlation confirms this intuition. As shown in the Internet Appendix, the correlation exhibits the same properties as the other estimated parameters. If its increasing pattern was driving our results, CE rates for short investment horizons would be affected in the same way as those for medium and long ones. This is not the case: according to Table 3, CE rates decrease or increase very slightly (and not monotonically) with $h$ for investment horizons up to one year. It is only for $T$ longer than one year that CE rates increase sharply and steadily with the prediction horizon.

\subsection{Portfolio compositions}

Adopting a prediction horizon of several years instead of one month leads to spectacularly larger $R^{2} s$ of the predictive regressions. These results translate into increases in the optimal CE rates. A natural question then arises as to the portfolio's risk exposure. The percentages of wealth invested in risky (stocks and bonds) assets that help explain, and reflect, the CE rates displayed in Table 3 are reported in Table 5.

For a given prediction horizon, the proportion of risky assets increases steadily with the investment horizon, in accordance with the professional conventional wisdom. The other, striking finding is that we do not observe such a monotonic and quantitatively important pattern across prediction horizons. The proportion is hump-shaped but tends to increase with $h$ for long-term 
investors ( $T>10$ years); it is hump-shaped but tends to decrease for the other investors, especially the short-run ones. This implies that the substantial increase in the CE rate is not obtained by unrealistic portfolio composition. As we have not imposed leverage or liquidity constraints on the portfolio, the proportions of wealth devoted to risky assets are rather large. Still, they remain in an acceptable range given that we have selected a risk aversion coefficient $\gamma$ significantly smaller (5) than is usually assumed in empirical research (routinely from 7 to 10). For example, for a 30-year investment horizon, the CE rate rises from $9.33 \%$ to $19.51 \%$ (a $109 \%$ jump) when the prediction horizon increases from 1 month to 10 years. Yet, the proportion of risky assets rises from $230 \%$ to $301 \%$ only (a $31 \%$ increase). This (unconstrained) finding is very encouraging as to the potential value added by LHP.

Overall, although we should bear in mind that the CE rates do not increase monotonically with $h$, our results indicate that LHP translates into potentially sizable welfare gains. When the prediction horizon is enlarged, investors in general benefit from the information that has accumulated. Therefore, they can more effectively exploit asset return predictability and improve their welfare. It now remains to be seen whether this economically meaningful result survives the correction for overlapping observations.

\section{Correcting for overlapping observations}

For return periods $h$ longer than one month, observations overlap. This creates spurious persistence in the residuals of the regression of the excess returns on the predictors. To check whether our results are robust to the correction for this persistence, we adopt the method proposed by Valkanov (2003). According to his Theorem 3 (on p. 208), one may obtain consistent estimates of the slopes of the predictive regressions if the stock excess return is regressed on the predictors' long period values, the latter being computed as the sum of the predictors' monthly values over the $h$-long period. We thus have to re-identify the parameters of the excess return processes. We run the following regression for the stock excess returns:

$$
r_{M, t, t+h}-\int_{t}^{t+h} r_{s} d s=a_{M, h}+\beta_{M, h, 1} \sum_{i=0}^{h / \Delta t-1} z_{1, t+i \Delta t}+\beta_{M, h, 2} \sum_{i=0}^{h / \Delta t-1} z_{2, t+i \Delta t}+\xi_{M, t, t+h}
$$

as an alternative to Eq. (24), in accordance with the analysis in Section 3.2 above, in particular Eq. (23). The prediction regression for the bond excess returns is similar.

\subsection{Parameter Estimates}

Using the same parameters for the dynamics of the predictors as in subsection 4.2 above since they are left unaffected, we re-estimate those for the stock and bond excess returns for all prediction 


\section{Table 6: Parameters Estimates with Valkanov's correction}

Panels A and B display the estimated parameters of the processes followed by the stock market return and the 10-year bond return, respectively. The period is 1942:M1 to 2016:M12 (900 observations). Panel A: Parameters for the stock market

\begin{tabular}{lccccccccccccc} 
& $\mathbf{1 m}$ & $\mathbf{3 m}$ & $\mathbf{6 m}$ & $\mathbf{1 y}$ & $\mathbf{3 y}$ & $\mathbf{5 y}$ & $\mathbf{7 y}$ & $\mathbf{9 y}$ & $\mathbf{1 0 y}$ & $\mathbf{1 5 y}$ & $\mathbf{2 0 y}$ & $\mathbf{2 5 y}$ & $\mathbf{3 0 y}$ \\
\hline $\mathbf{1 m}$ & 0.87 & 0.88 & 0.89 & 0.91 & 1.01 & 1.13 & 1.24 & 1.34 & 1.39 & 1.59 & 1.72 & 1.80 & 1.85 \\
$\mathbf{3 m}$ & 0.73 & 0.74 & 0.75 & 0.76 & 0.82 & 0.88 & 0.93 & 0.98 & 1.01 & 1.10 & 1.17 & 1.21 & 1.23 \\
$\mathbf{6 m}$ & 0.64 & 0.65 & 0.66 & 0.69 & 0.77 & 0.82 & 0.87 & 0.90 & 0.92 & 0.97 & 1.00 & 1.02 & 1.03 \\
$\mathbf{1 y}$ & 0.63 & 0.63 & 0.64 & 0.66 & 0.70 & 0.72 & 0.74 & 0.75 & 0.76 & 0.78 & 0.79 & 0.79 & 0.79 \\
$\mathbf{2 y}$ & 0.62 & 0.61 & 0.60 & 0.58 & 0.54 & 0.52 & 0.52 & 0.52 & 0.52 & 0.52 & 0.52 & 0.53 & 0.53 \\
$\mathbf{3 y}$ & 0.79 & 0.76 & 0.72 & 0.65 & 0.52 & 0.47 & 0.45 & 0.43 & 0.43 & 0.42 & 0.42 & 0.42 & 0.42 \\
$\mathbf{4 y}$ & 1.02 & 0.97 & 0.90 & 0.79 & 0.58 & 0.50 & 0.46 & 0.44 & 0.43 & 0.41 & 0.40 & 0.40 & 0.39 \\
$\mathbf{5 y}$ & 0.93 & 0.89 & 0.84 & 0.76 & 0.59 & 0.52 & 0.48 & 0.46 & 0.45 & 0.43 & 0.42 & 0.41 & 0.41 \\
$\mathbf{6 y}$ & 0.89 & 0.86 & 0.81 & 0.73 & 0.56 & 0.48 & 0.44 & 0.42 & 0.41 & 0.38 & 0.37 & 0.36 & 0.36 \\
$\mathbf{7 y}$ & 0.99 & 0.95 & 0.90 & 0.81 & 0.61 & 0.52 & 0.47 & 0.44 & 0.44 & 0.41 & 0.40 & 0.40 & 0.40 \\
$\mathbf{8 y}$ & -3.94 & -4.50 & -5.75 & -13.12 & 3.45 & 1.76 & 1.31 & 1.11 & 1.05 & 0.89 & 0.83 & 0.79 & 0.78 \\
$\mathbf{9 y}$ & 9.12 & 6.69 & 4.59 & 2.61 & 0.83 & 0.52 & 0.42 & 0.38 & 0.36 & 0.33 & 0.32 & 0.31 & 0.31 \\
$\mathbf{1 0 y}$ & -3.14 & -3.23 & -3.40 & -3.96 & 45.59 & 2.86 & 1.56 & 1.14 & 1.03 & 0.76 & 0.65 & 0.61 & 0.58
\end{tabular}

Panel B: Parameters for the 10-year bond

\begin{tabular}{lcccccccccccccc} 
& $\mathbf{1 m}$ & $\mathbf{3 m}$ & $\mathbf{6 m}$ & $\mathbf{1 y}$ & $\mathbf{2 y}$ & $\mathbf{3 y}$ & $\mathbf{4 y}$ & $\mathbf{5 y}$ & $\mathbf{6 y}$ & $\mathbf{7 y}$ & $\mathbf{8 y}$ & $\mathbf{9 y}$ & $\mathbf{1 0 y}$ \\
\hline$\mu_{0}$ & 0.006 & 0.007 & 0.013 & 0.021 & 0.032 & 0.037 & 0.041 & 0.044 & 0.045 & 0.044 & 0.034 & 0.046 & 0.044 \\
$\mu_{1}$ & -0.439 & -0.777 & -1.001 & -1.215 & -1.409 & -1.440 & -1.449 & -1.519 & -1.468 & -1.456 & -1.256 & -1.500 & -1.353 \\
$\mu_{2}$ & 3.329 & 4.449 & 4.716 & 4.610 & 4.114 & 3.615 & 3.111 & 2.922 & 2.741 & 2.724 & 2.262 & 2.525 & 1.792 \\
$\mathbf{L R}$ Mean = BP & 0.024 & 0.026 & 0.027 & 0.028 & 0.029 & 0.028 & 0.028 & 0.028 & 0.029 & 0.029 & 0.020 & 0.029 & 0.023 \\
$\sigma$ & 0.089 & 0.090 & 0.088 & 0.087 & 0.085 & 0.082 & 0.083 & 0.085 & 0.084 & 0.084 & 0.077 & 0.086 & 0.081 \\
$S R$ & 0.271 & 0.291 & 0.311 & 0.319 & 0.338 & 0.345 & 0.340 & 0.327 & 0.342 & 0.349 & 0.263 & 0.337 & 0.289 \\
corr(r,bond) & -0.208 & -0.376 & -0.424 & -0.462 & -0.525 & -0.495 & -0.488 & -0.514 & -0.519 & -0.514 & -0.518 & -0.479 & -0.488 \\
corr(dy,bond) & -0.129 & -0.094 & -0.078 & -0.150 & -0.214 & -0.226 & -0.201 & -0.175 & -0.188 & -0.229 & -0.258 & -0.287 & -0.285 \\
corr(def,bond) & 0.229 & 0.284 & 0.170 & 0.034 & -0.121 & -0.255 & -0.273 & -0.239 & -0.245 & -0.261 & -0.200 & -0.183 & -0.173 \\
corr(mkt,bond) & 0.078 & 0.036 & 0.043 & 0.170 & 0.285 & 0.374 & 0.402 & 0.420 & 0.495 & 0.577 & 0.625 & 0.675 & 0.678
\end{tabular}

periods $h$ (except one month) using Valkanov's correction. Results are reported in Panels A and B of Table 6, which are analogous to Panels B and C of Table 2.

Comparing Panel A with Panel B of Table 2 shows that the correction has a substantial impact on the long-run mean of the equity excess return $(E P)$, although it keeps its hump-shaped pattern with values lower for long prediction horizons than for short ones. EP ranges between $5.61 \%$ and $6.83 \%$ before correction and between $5.09 \%$ and $7.70 \%$ after. In addition, its volatility significantly decreases with $h$ larger than one year, indicating that stocks are less risky at longer terms, as often claimed. Yet, interestingly, we do not observe a systematic improvement in the risk-return tradeoff as the Sharpe ratio is rather stable (slightly humped) across the board. The absolute values of the correlations between the stock market and the predictors are now somewhat lower for return 
periods longer than one year, an expected result since the predictors become less persistent as the prediction horizon enlarges.

As to the bond excess returns, three results emerge from the comparison of Panel $\mathrm{C}$ of Table 2 with Panel B of Table 6. First, its mean excess return BP is essentially left unchanged. Second, its correlations with the predictors are smaller, in absolute value and the more so when $h$ is large, as expected. Third, its volatility now tends to decrease with $h$, which improves the Sharpe ratio for longer prediction horizons.

Correcting for overlapping observations thus does affect parameters' estimates. The final step is to assess the impact of these changes on CE rates and then on portfolio compositions.

\subsection{Impact on welfare and portfolio choice}

We compute the CE spreads generated by the new optimal strategies, displayed in Table 7, and compare them with those obtained without correction for overlapping observations (see Table 4).

We thus performed again the 1,000 simulations, using Valkanov's correction for the parameter estimation. Panel A of Table 7 displays the mean of the CE spreads. Panel B reports the NeweyWest t-stats relative to the means. ${ }^{19}$ With rare exceptions, these t-stats are extremely significant.

Results tend to confirm those of Section 5, although in a less clear cut manner. For investment horizons up to 7 years, CE spreads are positive and increase almost monotonically with the prediction period, and for investment horizons between 8 and 25 years, CE spreads are positive for $h=10$ years. Spreads are negative only for the 30-year investment horizon.

Overall, at both short and long horizons asset returns are predictable (here, by the dividend yield and the default spread, and, as shown in the Internet Appendix, by market volatility and term spread), and the positive impact on investors' portfolio performance and welfare is sizable. In almost all cases, CE rates are larger, sometimes notably so, at prediction horizons longer than one month and, in the majority of cases, this finding survives Valkanov's correction. LHP thus retains its potential value and does not appear to spring spuriously from using overlapping observations. However, since the added value of LHP does not increase monotonically with $h$, the fact that the $R^{2}$ s of the stock and bond excess return dynamics does not in itself guarantee that welfare improves with the length of the prediction horizon.

\section{Out-of-Sample Analysis}

Finally, it remains to be seen whether our in-sample results survive out of sample (OOS). While such an OOS exercise is straightforward when considering static investors, which is typically the case in the asset allocation literature with a one-month investment horizon, it is much more challenging in

\footnotetext{
${ }^{19}$ The Internet Appendix provides the CE rates from which spreads are obtained. To gain space, OLS t-stats are not shown as they are almost identical to Newey-West ones.
} 


\section{Table 7: Simulated Certainty Equivalent Spreads}

This Table is analogous to Table 4 except that we use Valkanov's correction for overlapping data when estimating the parameters. Panel A displays the mean spreads (computed over the 1,000 simulations). Panel B exhibits the Newey-West t-stats relative to these means, the adopted number of lags being equal to the estimation horizon minus 1. The sample period is 1942:M1 to 2016:M12.

\section{Panel A: Mean Spreads}

\begin{tabular}{|c|c|c|c|c|c|c|c|c|c|c|c|c|c|}
\hline & $1 \mathrm{~m}$ & $3 m$ & $6 \mathrm{~m}$ & $1 y$ & $2 y$ & $3 y$ & $4 y$ & $5 y$ & $6 y$ & $7 y$ & $8 y$ & $9 y$ & $10 y$ \\
\hline $1 \mathrm{~m}$ & & 0.37 & 0.45 & 0.48 & 0.49 & 0.57 & 0.69 & 0.66 & 1.01 & 1.22 & 1.19 & 1.76 & 2.68 \\
\hline $3 \mathrm{~m}$ & & 0.37 & 0.46 & 0.49 & 0.52 & 0.59 & 0.72 & 0.70 & 1.04 & 1.24 & 1.20 & 1.80 & 2.74 \\
\hline $6 \mathrm{~m}$ & & 0.37 & 0.46 & 0.50 & 0.54 & 0.62 & 0.75 & 0.73 & 1.07 & 1.27 & 1.21 & 1.85 & 2.79 \\
\hline $1 y$ & & 0.35 & 0.45 & 0.50 & 0.54 & 0.63 & 0.77 & 0.77 & 1.09 & 1.30 & 1.22 & 1.90 & 2.85 \\
\hline $3 y$ & & 0.16 & 0.24 & 0.29 & 0.35 & 0.45 & 0.59 & 0.64 & 0.93 & 1.15 & 1.07 & 1.78 & 2.64 \\
\hline $5 y$ & & -0.04 & -0.01 & 0.02 & 0.08 & 0.17 & 0.30 & 0.36 & 0.63 & 0.83 & 0.77 & 1.43 & 2.23 \\
\hline $7 y$ & & -0.21 & -0.21 & -0.20 & -0.16 & -0.09 & 0.02 & 0.08 & 0.33 & 0.51 & 0.45 & 1.08 & 1.83 \\
\hline $10 y$ & & -0.38 & -0.43 & -0.45 & -0.44 & -0.39 & -0.31 & -0.27 & -0.06 & 0.10 & 0.02 & 0.63 & 1.33 \\
\hline $15 y$ & & -0.54 & -0.64 & -0.70 & -0.75 & -0.74 & -0.68 & -0.68 & -0.51 & -0.38 & -0.50 & 0.08 & 0.73 \\
\hline $20 y$ & & -0.62 & -0.75 & -0.85 & -0.93 & -0.94 & -0.91 & -0.93 & -0.79 & -0.70 & -0.83 & -0.29 & 0.34 \\
\hline $25 y$ & & -0.65 & -0.81 & -0.92 & -1.03 & -1.07 & -1.06 & -1.09 & -0.97 & -0.90 & -1.04 & -0.53 & 0.07 \\
\hline $30 y$ & & -0.67 & -0.85 & -0.97 & -1.10 & -1.15 & -1.15 & -1.20 & -1.10 & -1.04 & -1.20 & -0.71 & -0.11 \\
\hline
\end{tabular}

Panel B: Newey - West $t$-Statistics

\begin{tabular}{|c|c|c|c|c|c|c|c|c|c|c|c|c|}
\hline $1 \mathrm{~m}$ & $3 \mathrm{~m}$ & $6 \mathrm{~m}$ & $1 y$ & $2 y$ & $3 y$ & $4 y$ & $5 y$ & $6 y$ & $7 y$ & $8 y$ & $9 y$ & $10 y$ \\
\hline $1 \mathrm{~m}$ & 47.5 & 38.7 & 30.9 & 21.3 & 18.0 & 17.1 & 14.3 & 19.5 & 22.2 & 18.9 & 27.1 & 31.0 \\
\hline $3 \mathrm{~m}$ & 47.4 & 38.8 & 31.3 & 21.6 & 18.2 & 17.1 & 14.6 & 19.4 & 22.0 & 18.9 & 27.3 & 31.1 \\
\hline $6 \mathrm{~m}$ & 45.7 & 38.0 & 31.1 & 21.5 & 18.0 & 16.9 & 14.8 & 19.3 & 21.6 & 18.8 & 27.3 & 31.1 \\
\hline $1 y$ & 40.5 & 34.6 & 29.1 & 20.6 & 17.3 & 16.4 & 14.7 & 18.8 & 21.1 & 18.6 & 27.4 & 31.2 \\
\hline $3 y$ & 14.4 & 15.2 & 14.6 & 12.7 & 11.7 & 12.1 & 11.7 & 15.6 & 17.9 & 16.5 & 25.8 & 30.3 \\
\hline $5 y$ & -3.3 & -0.7 & 1.1 & 2.8 & 4.4 & 6.1 & 6.6 & 10.7 & 13.3 & 12.0 & 22.0 & 27.3 \\
\hline $7 y$ & -13.8 & -10.7 & -8.4 & -5.1 & -2.1 & 0.5 & 1.5 & 5.6 & 8.2 & 7.0 & 17.0 & 23.5 \\
\hline $10 y$ & -23.2 & -20.1 & -17.6 & -13.5 & -9.4 & -6.2 & -5.0 & -1.0 & 1.6 & 0.2 & 10.0 & 17.6 \\
\hline $15 y$ & -31.6 & -28.7 & -26.3 & -21.5 & -16.9 & -13.4 & -12.2 & -8.6 & -5.9 & -7.7 & 1.3 & 9.8 \\
\hline $20 y$ & -35.4 & -33.1 & -31.0 & -25.9 & -21.2 & -17.7 & -16.5 & -13.3 & -10.8 & -12.7 & -4.6 & 4.6 \\
\hline $25 y$ & -37.1 & -35.6 & -33.7 & -28.6 & -23.8 & -20.4 & -19.2 & -16.3 & -14.0 & -16.0 & -8.5 & 1.0 \\
\hline $30 y$ & -37.6 & -36.8 & -35.3 & -30.3 & -25.5 & -22.1 & -21.0 & -18.4 & -16.1 & -18.4 & -11.3 & -1.5 \\
\hline
\end{tabular}


a dynamic, intertemporal setting. We first estimate the parameters over a burn-out period, before rolling the window. As usual, there is a tension here as the estimation period should be neither too short, to ensure the quality of the estimates), nor too long, to make room for a significant OOS period. The half-life of the predictors and the interest rate can guide our choice. The dividend yield is very persistent, exhibiting an autoregressive coefficient of 0.9882 at the one-month frequency. Its half-life is 58 years $(-\log (2) / \log (0.9882))$. Those of the default spread and interest rate are 24 and 23 years, respectively. We thus opt for a burnt-out window of 38 years, close to the average of the previous three half-lives. We then obtain 432, 408 and 384 valid OOS realizations for 1-year, 3 -year and 5-year investment horizons, respectively, which allows for a significant perspective on the findings.

We proceed as follows. Using the 38-year window, we estimate the parameters to be used over the whole investment period. We do not update the parameters during the investment period lest the strategy would become time inconsistent. Initial investment is one dollar and the portfolio is rebalanced every month. We report in Table 8 the accumulated wealth as well as the corresponding CEs, both in dollars and annual percentages. Figure 1 provides details for yearly mean returns for the 1-year, 3-year and 5-year investment horizons. The prediction horizon $h$ is 1, 12, 36 and 60 months.

LHP is unquestionably valuable out-of-sample also. For the 1-year and 3-year investment horizons, the OOS performance increases steadily (almost monotonically) up to $h=3$ years, and is still significantly better for $\mathrm{h}=4$ years than for $\mathrm{h}=1$ month. For the 5 -year investment horizon, the OOS performance increases virtually monotonically up to $h=4$ years. Only for $h=5$ are the results out-of-line.

\section{Conclusion}

The upshot of this research is that, although the dramatic increase in the predictive regression $R^{2}$ s obtained by lengthening the prediction horizon does not translate in a comparable increase in welfare and the relationship between the length of the return period (prediction horizon) and the $\mathrm{CE}$ rate is weaker and not necessarily monotonic, LHP has economic value.

The econometric method we use to obtain the parameters of the predictive regressions and of the stock and bond excess returns when the prediction horizon is longer than one period is novel regarding asset allocation. Instead of mechanically inferring these parameters from those obtained from the one-period prediction horizon, we let the data choose what are the best parameters for each and every prediction horizon. Also, we distinguish the latter from the investment horizon. The influence predictability exerts on the composition and CE return rate of optimal portfolios is generally more pronounced for longer prediction horizons, although the extent of this result

depends on the investor's horizon. In addition, it does not crucially depend on whether estimates of the parameters for excess returns are corrected for the persistence in residuals generated by 


\section{Table 8: Summary Statistics of Out-of-sample Returns}

We report various statistics for the out-of-sample returns on wealth for three investment horizons $(1,3$ and 5 years). $S R$ stands for the Sharpe ratio computed over the period. The certainty equivalent in dollars $(C E(\$))$ and annualized in percentage $(C E(\%))$ is computed for a risk aversion equal to 5 .

\section{Panel A: 1-year investment horizon}

\begin{tabular}{lcccccccc} 
& $\mathbf{1 m}$ & $\mathbf{3 m}$ & $\mathbf{6 m}$ & $\mathbf{1 y}$ & $\mathbf{2 y}$ & $\mathbf{3 y}$ & $\mathbf{4 y}$ & $\mathbf{5 y}$ \\
\hline Mean (yearly, \%) & 8.382 & 8.487 & 8.565 & 8.197 & 9.328 & 10.119 & 9.321 & 6.725 \\
Std (yearly, \%) & 9.409 & 8.619 & 8.401 & 7.929 & 9.683 & 11.383 & 10.656 & 11.710 \\
Min (yearly, \%) & -13.065 & -11.624 & -10.055 & -8.992 & -8.799 & -11.236 & -11.133 & -29.248 \\
Max (yearly, \%) & 31.419 & 28.059 & 27.946 & 26.120 & 34.858 & 41.493 & 37.186 & 30.103 \\
Skewness & -0.127 & -0.172 & -0.021 & 0.099 & 0.671 & 0.650 & 0.413 & -0.869 \\
Kurtosis & 3.328 & 3.102 & 2.986 & 2.949 & 3.497 & 3.501 & 3.147 & 4.488 \\
SR & 0.891 & 0.985 & 1.020 & 1.034 & 0.963 & 0.889 & 0.875 & 0.574 \\
CE (\$) & 1.062 & 1.067 & 1.069 & 1.067 & 1.074 & 1.074 & 1.068 & 1.023 \\
CE (\%) & 6.217 & 6.681 & 6.897 & 6.738 & 7.357 & 7.423 & 6.839 & 2.350
\end{tabular}

Panel B: 3-year investment horizon

\begin{tabular}{lcccccccc} 
& $\mathbf{1 m}$ & $\mathbf{3 m}$ & $\mathbf{6 m}$ & $\mathbf{1 y}$ & $\mathbf{2 y}$ & $\mathbf{3 y}$ & $\mathbf{4 y}$ & $\mathbf{5 y}$ \\
\hline Mean & 8.958 & 9.370 & 9.571 & 9.208 & 9.671 & 10.453 & 10.170 & 7.065 \\
Std & 5.397 & 5.076 & 4.768 & 4.317 & 4.649 & 5.985 & 6.220 & 9.483 \\
Min & -4.787 & -2.863 & -1.748 & -0.546 & 2.729 & 1.140 & -0.667 & -25.397 \\
Max & 20.426 & 19.669 & 18.726 & 18.495 & 20.533 & 24.579 & 25.169 & 20.491 \\
Skewness & -0.309 & -0.214 & -0.220 & 0.015 & 0.604 & 0.625 & 0.536 & -1.922 \\
Kurtosis & 3.284 & 2.926 & 2.753 & 2.760 & 2.573 & 2.756 & 2.932 & 7.291 \\
SR & 1.660 & 1.846 & 2.007 & 2.133 & 2.080 & 1.747 & 1.635 & 0.745 \\
CE (\$) & 1.226 & 1.251 & 1.265 & 1.263 & 1.279 & 1.282 & 1.265 & 0.838 \\
CE (\%) & 7.035 & 7.741 & 8.149 & 8.093 & 8.537 & 8.640 & 8.150 & -5.726
\end{tabular}

Panel C: 5-year investment horizon

\begin{tabular}{lcccccccc} 
& $\mathbf{1 m}$ & $\mathbf{3 m}$ & $\mathbf{6 m}$ & $\mathbf{1 y}$ & $\mathbf{2 y}$ & $\mathbf{3 y}$ & $\mathbf{4 y}$ & $\mathbf{5 y}$ \\
\hline Mean & 9.124 & 9.847 & 10.211 & 9.881 & 10.224 & 11.154 & 11.215 & 8.536 \\
Std & 4.589 & 4.581 & 4.454 & 4.098 & 4.347 & 5.469 & 5.447 & 6.815 \\
Min & 0.646 & 1.962 & 2.706 & 3.114 & 2.903 & 1.749 & 2.284 & -11.173 \\
Max & 18.900 & 19.169 & 19.253 & 18.785 & 20.941 & 25.434 & 25.674 & 20.747 \\
Skewness & 0.093 & 0.158 & 0.167 & 0.252 & 0.579 & 0.773 & 0.827 & -1.075 \\
Kurtosis & 2.295 & 2.169 & 2.150 & 2.283 & 3.024 & 3.422 & 3.420 & 4.748 \\
SR & 1.988 & 2.150 & 2.293 & 2.411 & 2.352 & 2.040 & 2.059 & 1.252 \\
CE (\$) & 1.416 & 1.469 & 1.501 & 1.498 & 1.516 & 1.531 & 1.541 & 1.057 \\
CE (\%) & 7.204 & 7.996 & 8.468 & 8.414 & 8.678 & 8.896 & 9.027 & 1.107
\end{tabular}




\section{Figure 1: Out of Sample Returns}

This Figure displays the out-of-sample returns on wealth for three investment horizons (1, 3 and 5 years, column-wise) and four prediction horizons (1 month, 1, 3 and 5 years, row-wise.
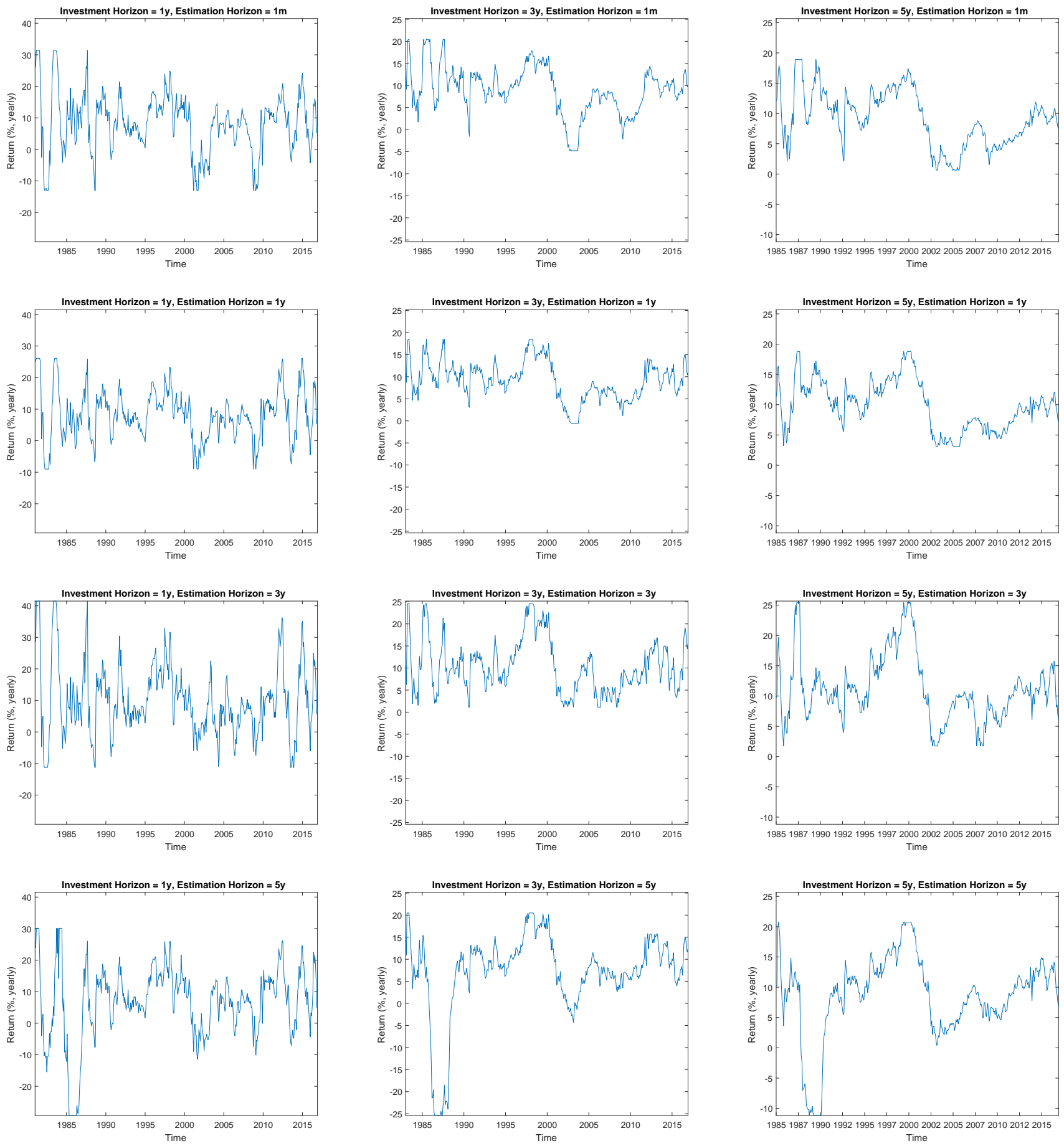
overlapping observations.

This work can be extended in at least two directions. First, it could be generalized to incorporate other sources of uncertainty that investors face in practice, such as model uncertainty or preference for robustness, estimation risk, and uncertainty about current and future expected returns in the spirit of Pastor and Stambaugh (2012). These are, however, serious and difficult challenges because of inference issues and the dynamic nature of the portfolio optimization program. Second, the argument put forward in this paper could be also applied to the numerous papers that use long-horizon returns to test asset pricing models. While most papers proceed by inferring long-horizon returns from short-horizon ones, our work suggests that using genuine long-horizon returns may yield substantially different results.

\section{References}

Amihud, Y., C. Hurvich and Y. Wang, 2008, Multiple-Predictor Regressions: Hypothesis Testing, Review of Financial Studies 22, 414-434.

Baker, M. and J. Wurgler, 2000, The equity share in new issues and aggregate stock returns, The Journal of Finance, 55(5), 2219-2257.

Bandi, F. and B. Perron, 2008, Long-run risk-return trade-offs, Journal of Econometrics, 143(2), 349-374.

Bandi, F. M., Perron, B., Tamoni, A., Tebaldi, C., 2018, The scale of predictability, Working Paper.

Barberis, N. and R. Thaler, 2003, A Survey of Behavioral Finance, in Handbook of the Economics of Finance, G. Constantinides, R. Stulz, M. Harris eds., North Holland, Amsterdam.

Bianchi, D. and A. Tamoni, 2017, The Dynamics of Expected Returns: Evidence from Multi-Scale Time Series Modeling, Working Paper.

Boudoukh, J., M. Richardson and R. Whitelaw, 2008, The myth of long-horizon predictability, Review of Financial Studies 21, 1577-1605.

Brandt, M., 2010, Portfolio choice problems, in Y. Ait-Sahalia and L.P. Hansen (eds.), Handbook of Financial Econometrics, Volume 1: Tools and Techniques, North Holland, 269-336.

Brennan, M. and Y. Xia, 2010, Persistence, Predictability, and Portfolio Planning, in Handbook of Quantitative Finance and Risk Management, Cheng-Few Lee and John Lee Eds, Springer.

Calvet, L. E. and A. J. Fisher, 2007, Multifrequency news and stock returns, Journal of Financial Economics, 86(1), 178-212.

Campbell, J. Y., 2017, Financial Decisions and Markets: A Course in Asset Pricing. Princeton University Press.

Campbell, J., A. Lo and C. MacKinlay, 1997, The Econometrics of Financial Markets. Princeton, NJ: Princeton University Press.

Campbell, J. and R. Shiller, 1988, The dividend-price ratio and expectations of future dividends and discount factors, Review of Financial Studies, 1, 195-228.

Campbell, J. and L. Viceira, 2005, The Term Structure of the Risk-Return Trade-Off, Financial Analysts Journal 61(1), 34-44.

Carmona, J., A. León and A. Vaello-Sebastià, 2012, Does stock return predictability affect ESO fair value? European Journal of Operational Research 223, 188-202. 
Carroll, R., T. Conlon, J. Cotter and E. Salvador, 2017, Asset allocation with correlation: A composite trade-off, European Journal of Operational Research 262, 1164-1180.

Cochrane, J., 1999, Portfolio advice for a multifactor world (No. w7170), National Bureau of Economic Research.

Cochrane, J., 2005, Asset Pricing, Princeton, NJ: Princeton University Press.

Dew-Becker, I. and S. Giglio, 2016, Asset pricing in the frequency domain: theory and empirics, The Review of Financial Studies, 29(8), 2029-2068.

Fama, E. and K. French, 1988, Dividend yields and expected stock returns, Journal of Financial Economics, 22, 3-25.

Fama, E. and K. French, 1989, Business conditions and expected returns on stocks and bonds, Journal of Financial Economics 25, 23-49.

Fama, E. and K. French, 2018, Long-Horizon Returns, The Review of Asset Pricing Studies, forthcoming.

Favero, C. A., Ortu, F., Tamoni, A., Yang, H., 2017, Implications of Return Predictability across Horizons for Asset Pricing Models, Working Paper.

Fuster, A., Hebert, B., Laibson, D., 2010, Investment dynamics with natural expectations, International journal of central banking/Bank of Canada, 8(81), 243.

Goyal, A. and I. Welch, 2007, A comprehensive look at the empirical performance of equity premium prediction, The Review of Financial Studies, 21(4), 1455-1508.

Hansen, L. and R. Jagannathan, 1991, Implications of security market data for models of dynamic economies, Journal of political economy, 99(2), 225-262.

Huang, D. and G. Zhou, 2017, Upper bounds on return predictability, Journal of Financial and Quantitative Analysis 52 (2), 401-425.

Inoue, A. and K. Lutz, 2002, Bootstrapping autoregressive processes with possible unit roots, Econometrica 70(1), 377-391.

Kim, T. and E. Omberg, 1996, Dynamic nonmyopic portfolio behavior, Review of Financial Studies 9, 141-61.

Koijen, R. and S. Van Nieuwerburgh, 2011, Predictability of Returns and Cash Flows, Annual Review of Financial Economics 3, 467-491.

Kreiss, J. P. and S. Lahiri, 2012, Bootstrap methods for time series, Handbook of Statistics 30, $3-26$.

Lamont, O., 1998, Earnings and expected returns, The journal of Finance, 53(5), 1563-1587.

Lettau, M. and S. Ludvigson, 2001, Consumption, Aggregate Wealth, and Expected Stock Returns, Journal of Finance, 56, 815-849

Madan, D. and W. Schoutens, 2018, Self-similarity in Long Horizon Asset Returns, Working Paper.

Martin, I., 2017, What is the Expected Return on the Market?, The Quarterly Journal of Economics, 132(1), 367-43

Morell, J., 2018, The decline in the predictive power of the US term spread: A structural interpretation, Journal of Macroeconomics, 55, 314-331.

Moreno, D. and I. Olmeda, 2007, Is the predictability of emerging and developed stock markets really exploitable? European Journal of Operational Research 182, 436-454.

Pastor L. and R. Stambaugh, 2012, Are Stocks Really Less Volatile in the Long Run?, Journal of Finance 67, 431-478.

Poterba, J. and L. Summers, 1988, Mean reversion in stock prices: evidence and implications, Journal of Financial Economics 22, 27-59.

Poti, V., 2018, A new tight and general bound on return predictability, Economics Letters 162, 140-145. 
Ross, S.A., 2005. Neoclassical Finance. Princeton University Press.

Rossi, M., T. Simin and D. Smith, 2013, Return Predictability Under the Alternative, Working Paper.

Schmidt, M., 2011, Interest rate term structure modelling, European Journal of Operational Research 214, 1-14.

Stambaugh, R., 1999, Predictive regressions, Journal of Financial Economics 54, 375-421.

Valkanov, R., 2003, Long-Horizon Regressions: Theoretical Results and Applications, Journal of Financial Economics, 68, 201-232.

Wachter, J., 2010, Asset allocation, Annual Reviews of Financial Economics 2, 175-206.

Wang, Y., Liu, L., Ma, F., Diao, X., 2018, Momentum of return predictability, Journal of Empirical Finance, 45, 141-156.

Yao, H., Z. Li and D. Li, 2016, Multi-period mean-variance portfolio selection with stochastic interest rate and uncontrollable liability, European Journal of Operational Research 252, 837851. 